\title{
Virtual screening of potentially endocrine-disrupting chemicals against nuclear receptors and its application to identify PPARY-bound fatty acids
}

\author{
Chaitanya K. Jaladanki ${ }^{1,2} \cdot$ Yang He$^{3} \cdot \mathrm{Li} \mathrm{Na} \mathrm{Zhao}^{1} \cdot$ Sebastian Maurer-Stroh ${ }^{1,2} \cdot$ Lit-Hsin Loo $^{1,2} \cdot$ Haiwei Song $^{3} \cdot$ \\ Hao Fan $^{1}(1)$
}

Received: 2 July 2020 / Accepted: 27 August 2020 / Published online: 9 September 2020

(c) The Author(s) 2020

\begin{abstract}
Nuclear receptors (NRs) are key regulators of energy homeostasis, body development, and sexual reproduction. Xenobiotics binding to NRs may disrupt natural hormonal systems and induce undesired adverse effects in the body. However, many chemicals of concerns have limited or no experimental data on their potential or lack-of-potential endocrine-disrupting effects. Here, we propose a virtual screening method based on molecular docking for predicting potential endocrine-disrupting chemicals (EDCs) that bind to NRs. For 12 NRs, we systematically analyzed how multiple crystal structures can be used to distinguish actives and inactives found in previous high-throughput experiments. Our method is based on (i) consensus docking scores from multiple structures at a single functional state (agonist-bound or antagonist-bound), (ii) multiple functional states (agonist-bound and antagonist-bound), and (iii) multiple pockets (orthosteric site and alternative sites) of these NRs. We found that the consensus enrichment from multiple structures is better than or comparable to the best enrichment from a single structure. The discriminating power of this consensus strategy was further enhanced by a chemical similarity-weighted scoring scheme, yielding better or comparable enrichment for all studied NRs. Applying this optimized method, we screened 252 fatty acids against peroxisome proliferator-activated receptor gamma (PPAR $\gamma$ ) and successfully identified 3 previously unknown fatty acids with $\mathrm{Kd}=100-250 \mu \mathrm{M}$ including two furan fatty acids: furannonanoic acid (FNA) and furanundecanoic acid (FUA), and one cyclopropane fatty acid: phytomonic acid (PTA). These results suggested that the proposed method can be used to rapidly screen and prioritize potential EDCs for further experimental evaluations.
\end{abstract}

Keywords Virtual screening $\cdot$ In silico toxicity prediction $\cdot$ Nuclear receptors $\cdot$ EDC $\cdot$ ToxCast $\cdot$ Furan fatty acid

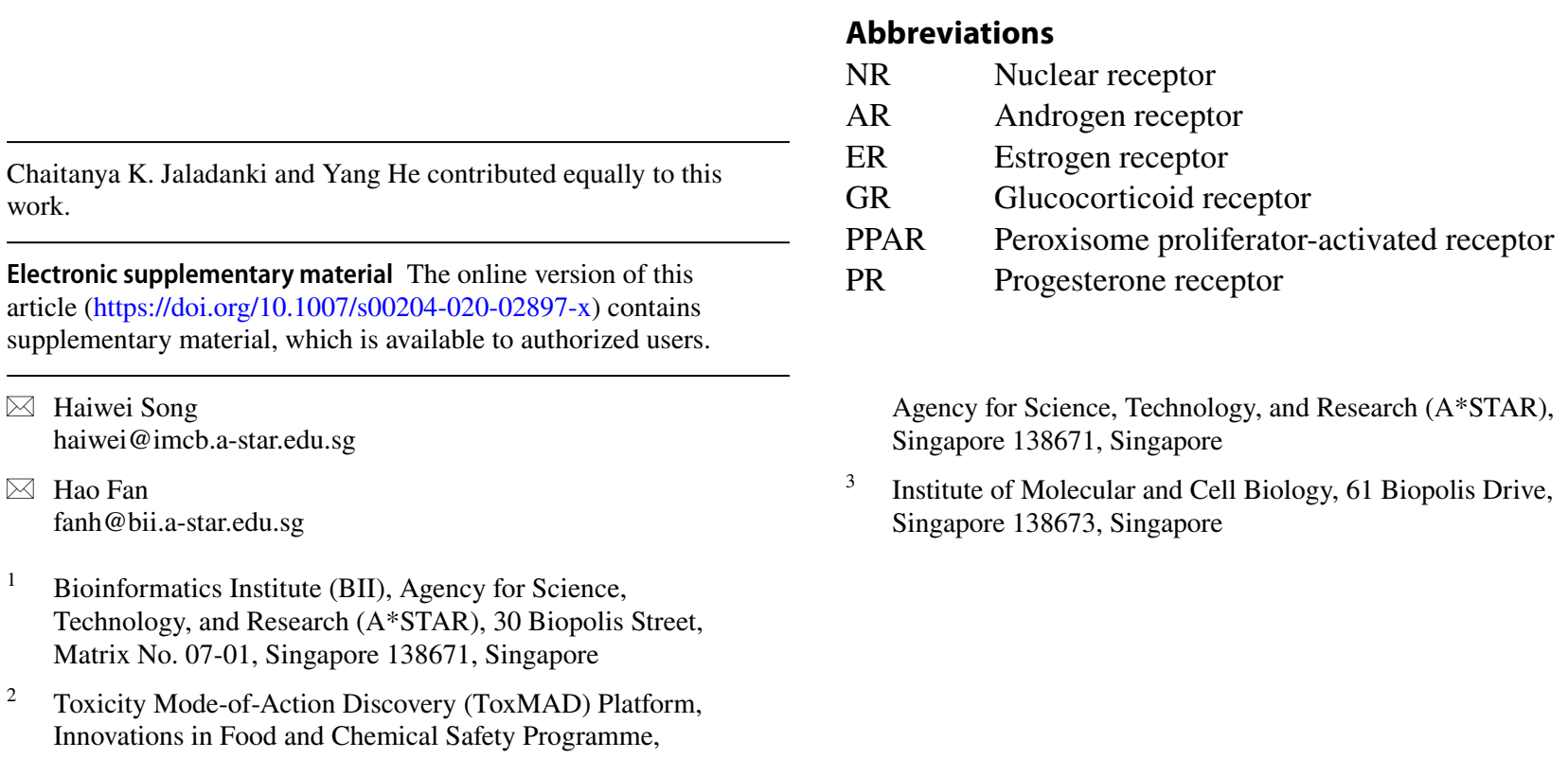




$\begin{array}{ll}\text { RAR } & \text { Retinoic acid receptor } \\ \text { RXR } & \text { Retinoic X receptor } \\ \text { VDR } & \text { Vitamin D receptor } \\ \text { ROR } & \text { RAR-related orphan receptor } \\ \text { LXR } & \text { Liver X receptor } \\ \text { EDC } & \text { Endocrine-disrupting chemical } \\ \text { US-EPA } & \text { United States environmental protection agency } \\ \text { PUFA } & \text { Polyunsaturated fatty acids } \\ \text { HTS } & \text { High-throughput in vitro screening } \\ \text { AUC } & \text { Area under the curve } \\ \text { RMSD } & \text { Root mean square deviation }\end{array}$

\section{Introduction}

Endocrine-disrupting chemicals (EDCs) are chemicals that can interfere with the natural hormonal systems in the body via various mechanisms, including altering the production, release, transport, binding, and metabolism of key hormones responsible for energy homeostasis, body development, and sexual reproduction (Weatherman et al. 1999; Sanderson 2006; Bain et al. 2007; Reif et al. 2010; Huang et al. 2010; Soto and Sonnenschein 2010; Rotroff et al. 2013; Toporova and Balaguer 2020). Humans are exposed to many potential EDCs that can be found in the environment, food, and consumer products. Therefore, it is not surprising that the identification of potential EDCs has been a central focus in predictive toxicology. The European Commission in Regulations, Registration, Evaluation, Authorization, and Restriction of Chemical (REACH) (European Council 2006) has listed EDCs as important toxicological endpoints for chemical registrations (Nicolotti et al. 2014). Moreover, the United States Environmental Protection Agency (US-EPA) is also focusing on EDCs under the Endocrine Disruptor Screening Program (EDSP).

EDCs may disrupt normal functions of the endocrine system by interacting with nuclear receptors (NRs) (Diamanti-Kandarakis et al. 2009; Reif et al. 2010; Soto and Sonnenschein 2010; Schug et al. 2011; Rotroff et al. 2013). For example, bisphenol-A (BPA) and its analogs, heavily used in the manufacture of polycarbonate plastics and epoxy resins, have been shown to bind to estrogen (ER) and androgen receptors (AR). The NR superfamily are ligandactivated transcription factors that regulate various physiological processes such as cell development, differentiation, proliferation, and metabolism. They are also associated with numerous pathologies such as reproductive abnormalities, inflammation, cardiovascular disease, and cancer. (Ribeiro et al. 1995; Bain et al. 2007). NRs are known to be activated by hormones, vitamins, fatty acids, and metabolites in the body. Members of this superfamily contain a $\mathrm{N}$-terminal transactivation domain (NTD), a zinc-finger DNA binding domain (DBD), and a C-terminal ligand-binding domain
(LBD). The binding of ligands with their associated NR transactive specific genes within a target tissue Ligand binding to its correlated NR results in the transactivation of specific genes within a target tissue (Weatherman et al. 1999; Bain et al. 2007). NRs may be subdivided into three mechanistic classes. Class I NRs, also called steroid receptors, include the ER, AR, progesterone receptor (PR), mineralocorticoid receptor (MR), and glucocorticoid receptor (GR). Class II NRs include the thyroid hormone receptors (TR $\alpha$ and $\beta$ ), peroxisome proliferator-activated receptors (PPAR $\alpha, \beta$, and $\gamma$ ), retinoic acid receptors (RAR $\alpha, \beta$, and $\gamma$ ), liver X receptors (LXR $\alpha$ and $\beta$ ), vitamin D receptor (VDR), and RAR-related orphan receptors (ROR $\alpha, \beta$, and $\gamma$ ) (Robinson-Rechavi et al. 2003; Bain et al. 2007). The members of this subfamily heterodimerize with retinoid $\mathrm{X}$ receptors $(\operatorname{RXR} \alpha, \beta$, and $\gamma)$. Class III NRs are a family of the orphan receptors. This NR class includes a group of proteins that share substantial sequence homology with known NRs but have not yet identified the ligands, such as small heterodimer partner (SHP), testicular receptor 2 and 4 (TR2 and 4), and estrogen-related receptor (ERR $\alpha, \beta$, and $\gamma$ ).

Despite the known importance of NRs and their natural ligands in regulating endocrine systems, the relatively large number of proteins in this family (many of which are still poorly studied) and the huge numbers of potential EDCs with high human exposure levels have made the efforts to identify NR-bound EDCs to be very challenging. Traditional animal studies are expensive, time consuming, and low throughput (European Council 2006; Dix et al. 2007; Judson et al. 2008, 2009; Cohen Hubal et al. 2010; Knudsen et al. 2011; Kavlock et al. 2012). Thus, most previous work has been focused on a few well-characterized NRs, such as ER, AR, and PR, and a small number of chemicals of concerned, such as BPA. To allow the screening of the biological activity of large numbers of chemicals more effective, US-EPA and several other agencies had initiated the Toxicity Forecaster (ToxCast) program and the Tox 21 consortium. Thousands of chemicals were screened and analyzed using high-throughput in vitro biochemical and cell-based assays that cover many key cellular pathways and biochemical targets relevant to toxicology (Dix et al. 2007). Several highly predictive in vitro cell-type-specific toxicity models based on phenotypic profiling have also been developed by the Agency for Science, Technology, and Research (A*STAR) from Singapore (Su et al. 2016; Lee et al. 2018; Paul Friedman et al. 2020; van der Ven et al. 2020; Hussain et al. 2020). These in vitro screening efforts have generated a large amount of invaluable bioactivity data for the tested chemicals, but many relevant environmental agents and/or food components are still not being tested. Therefore, computational or in silico methods have the potential to bridge the gap and predict the bioactivities of relevant chemicals with little or without any experimental data. 
Most existing computational methods for predicting potential EDCs are based on quantitative structure-activity relationship (QSAR) models (Shi et al. 2001; Nicolotti et al. 2008, 2009; Capuzzi et al. 2016) that require high chemical similarity to known binders (Capuzzi et al. 2016). However, the accuracy of these methods can be limited when applied to chemicals that belong to different scaffolds from known EDCs. To overcome this issue, protein structure-based docking or virtual screening can be employed, benefiting from the availability of three-dimensional structures of target receptors and providing insights into molecular recognition events. Such methods, primarily used in pharmaceutical ligand discovery programs, are intended to search large libraries of small molecules to suggest possible chemicals that can bind to a protein target with high affinity (Kitchen et al. 2004; Shoichet 2004; Nicolotti et al. 2008). To date, these approaches have not been widely used in toxicology, especially for the screening of potential EDCs from large numbers of chemicals. Given the enormous and fast-growing mass of protein structures and in vitro bioactivity data determined experimentally, structure-based docking or virtual screening method might provide an excellent tool to rapidly flag out potential EDCs for further experimental evaluations or confirmations of their adverse effects.

We have developed a structure-based virtual screening method to identify active EDCs against twelve human NRs (Weatherman et al. 1999; Bain et al. 2007; Huang et al. 2010; Toporova and Balaguer 2020) with ToxCast NR activity data, as well as multiple $(\geq 2)$ agonist-bound and antagonist-bound crystal structures of receptors. These NRs include AR, GR, PR, ER $\alpha, \mathrm{ER} \beta$ from the steroid receptor class, and PPAR $\alpha, \operatorname{PPAR} \gamma, \mathrm{RAR} \alpha, \mathrm{ROR} \gamma, \mathrm{VDR}, \mathrm{RXR} \alpha$, LXR $\beta$ from the thyroid/retinoid receptor class. Here, we present the method and its benchmark results using the ToxCast NR activity data, and its application to identify PPAR $\gamma$-bound fatty acids. Only a few previous studies had used molecular docking or virtual screening to predict the potential toxicological effects of NR ligands (Trisciuzzi et al. 2015, 2017). For example, Trisciuzzi et al. demonstrated that structure-based approaches, such as molecular docking, could be extended to exploratory toxicology studies, using ToxCast estrogenic potential and androgenic potential data (Trisciuzzi et al. 2015, 2017). Due to the aforementioned limitations, these studies focused only on one NR and failed to provide a complete picture of the capability of structurebased methods for EDC prediction. Furthermore, the protein target's flexibility is typically not taken completely into consideration (Knegtel et al. 1997; Fradera et al. 2002; Carlson 2002; McCammon 2005; Cavasotto and Singh 2008; Cozzini et al. 2008; Ma et al. 2009; Spyrakis and Cavasotto 2015). In our current study, for each of the 12 selected receptors, we included 2 agonist-bound and 2 antagonist-bound crystal structures, to systematically evaluate the utility of multiple receptor structures in EDC prediction using virtual screening.

To gain further insights on the use of virtual screening for EDC prediction, we explored the following questions. First, since multiple ligands are known for each receptor and ligand-based methods are orthogonal to the protein-based methods, we want to know whether the proposed method can better discriminate ToxCast actives from inactives when docking scores of screened chemicals are weighted by their chemical similarities to the known ligands. Second, given the fact that alternative binding pockets (ABP) have been confirmed for nuclear receptors such as AR and ROR $\gamma$, we investigated the possible impact of virtual screening against ABPs on ToxCast active prediction accuracy. Lastly, we performed a case study on fatty acids to demonstrate how the proposed method can be used in practice. Fatty acids are a large group of food components that can be found naturally in seafood, nuts and seeds, and plant oils, but also increasingly be used as food additives. They play important roles in human health and nutrition and some of them have been found active against nuclear receptors such as PPAR $\gamma$ (Kliewer et al. 1997; Xu et al. 1999; Kersten et al. 2000; Sampath and Ntambi 2004; Manco et al. 2004; Bordoni et al. 2006; Madrazo and Kelly 2008; Marion-Letellier et al. 2016). However, only 14 of them have been experimentally tested in the ToxCast program. We used the proposed method to screen 252 dietary-oriented fatty acids against PPAR $\gamma$ and experimentally verified that three of the top novel hits bind to PPAR $\gamma$ using surface plasmon resonance analysis. Together, our results demonstrate the feasibility of using virtual screening to prioritize suspected EDCs for further experimental evaluations.

\section{Materials and methods}

\section{ToxCast chemical benchmarking database}

The benchmarking database for all the NRs was obtained from the ToxCast database consisting of a curated repository of chemicals with high-quality experimental data (https://www.epa.gov/chemical-research/toxicity-forec aster-toxcasttm-data). The Tox $21 /$ ToxCast database released in October 2015, containing information for 9076 chemicals tested across 1193 different assays, including chemical names, CAS numbers, 2D structures, quality control grades, descriptions of the assays, and results summarized by AC50 values. These assays have been developed across multiple human and animal cell lines by several providers, including Attagene Inc. (ATG, one transactivation assay measuring reporter RNA transcript levels), NIH Chemical Genomics Center (Tox21, three transactivation assays measuring reporter protein level 
readouts), and NovaScreen (NVS, biochemical radioligand binding assays), BioSeek (BSK). In all assays, for each chemical-assay combination, a micromolar concentration was reported as the negative logarithm of the half-maximal activity concentration (pAC50), chemicals with " 1 " values for a given assay considered as active and with "0" values considered as inactive. For AR, PR, GR, PPAR $\alpha, \operatorname{PPAR} \gamma$, RAR $\alpha$, we selected chemicals that were screened in NVS assays because these chemicals were tested by biochemical radioligand binding assays that provide a measure of interaction between protein and ligands, as well as the degree of affinity (weak, strong, or no binding). For other nuclear receptors that do not have biochemical data we selected chemicals screened by cell-based assays, for $\operatorname{ROR} \gamma, \mathrm{VDR}$, RXR $\alpha$, and LXR $\beta$ from ATG and for ER $\alpha$ and ER $\beta$ from Tox 21 (Table 1). Furthermore, we discarded chemicals without defined structures (e.g. mixtures, oils), chemicals without a molecular description of their structure in

Table 1 Nuclear receptor targets

\begin{tabular}{|c|c|c|c|c|c|}
\hline Protein & Active structure PDB ID & Inactive structure PDB ID & Actives & Inactives & Assay \\
\hline $\mathrm{AR}^{*}$ & 3L $3 \mathrm{X} ; 2 \mathrm{AX} 9$ & 3RLJ; $2 \mathrm{OZ7}$ & 97 & 2561 & $\begin{array}{l}\text { Biochemical assay, single-readout assay that uses extracted } \\
\text { gene-proteins from MCF7 in a cell-free assay. Measure- } \\
\text { ments } 18 \mathrm{~h} \text { after chemical dosing in a 96-well plate }\end{array}$ \\
\hline GR & 3K22; 6EL9 & 1NHZ; 4MDD & 207 & 2351 & $\begin{array}{l}\text { Biochemical assay, single-readout assay that uses extracted } \\
\text { gene-proteins in a cell-free assay. Measurements were } \\
\text { taken } 16 \mathrm{~h} \text { after chemical dosing in a 96-well plate }\end{array}$ \\
\hline PR & 1SQN; 3KBA & $2 \mathrm{OVH} ; 4 \mathrm{OAR}$ & 57 & 2403 & $\begin{array}{l}\text { Biochemical assay, single-readout assay that uses extracted } \\
\text { gene-proteins from T47D in a cell-free assay. Measure- } \\
\text { ments were taken } 18 \mathrm{~h} \text { after chemical dosing in a 96-well } \\
\text { plate }\end{array}$ \\
\hline $\mathrm{ER} \alpha$ & 1X7R; 5U2D & $1 \mathrm{XP} 1 ; 2 \mathrm{IOK}$ & 119 & 1651 & $\begin{array}{l}\text { Biochemical assay, single-readout assay that uses extracted } \\
\text { gene-proteins from MCF7 in a cell-free assay. Measure- } \\
\text { ments } 18 \mathrm{~h} \text { after chemical dosing in a 96-well plate }\end{array}$ \\
\hline $\mathrm{ER} \beta$ & 3OLL;1U3R & 1L2J; 1NDE & 198 & 1582 & $\begin{array}{l}\text { Biochemical assay, single-readout assay that uses extracted } \\
\text { gene-proteins from MCF7 in a cell-free assay. Measure- } \\
\text { ments were taken } 18 \mathrm{~h} \text { after chemical dosing in a 96-well } \\
\text { plate }\end{array}$ \\
\hline $\operatorname{PPAR} \alpha$ & $2 \mathrm{P} 54 ; 1 \mathrm{I} 7 \mathrm{G}$ & 1KKQ; 2REW & 68 & 1701 & $\begin{array}{l}\text { Biochemical assay, single-readout assay that uses extracted } \\
\text { gene-proteins in a cell-free assay. After } 1 \mathrm{~h} \text { after chemical } \\
\text { dosing in a } 384 \text {-well plate }\end{array}$ \\
\hline $\operatorname{PPAR} \gamma$ & $3 \mathrm{BC} 5 ; 3 \mathrm{VSO}$ & 5DWL; 5LSG & 108 & 1660 & $\begin{array}{l}\text { Biochemical assay, single-readout assay that uses extracted } \\
\text { gene-proteins in a cell-free assay. Measurements were } \\
\text { taken } 2 \mathrm{~h} \text { after chemical dosing in a 384-well plate }\end{array}$ \\
\hline $\operatorname{RAR} \alpha$ & 3KMR; 3A9E & 1DKF; 5K13 & 48 & 1717 & $\begin{array}{l}\text { Biochemical assay, single-readout assay that uses extracted } \\
\text { gene-proteins in a cell-free assay. Measurements were } \\
\text { taken } 2 \mathrm{~h} \text { after chemical dosing in a 384-well plate }\end{array}$ \\
\hline $\mathrm{ROR} \gamma^{\#}$ & 3LOL; 4WLB & $5 \mathrm{NTK} ; 5 \mathrm{~K} 3 \mathrm{~N}$ & 57 & 3265 & $\begin{array}{l}\text { Cell-based assay, multiplexed-readout assay that uses } \\
\text { HepG2, a human liver cell line, with measurements taken } \\
\text { at } 24 \mathrm{~h} \text { after chemical dosing in a } 24 \text {-well plate }\end{array}$ \\
\hline VDR & 3В0T:3AZ2 & 5XPL:5XUQ & 951 & 2377 & $\begin{array}{l}\text { Cell-based assay, multiplexed-readout assay that uses } \\
\text { HepG2, a human liver cell line, with measurements taken } \\
\text { at } 24 \mathrm{~h} \text { after chemical dosing in a } 24 \text {-well plate }\end{array}$ \\
\hline $\mathrm{RXR} \alpha$ & 1MVC; 5LYQ & 3NSQ; 2P1V & 124 & 3204 & $\begin{array}{l}\text { Cell-based assay, multiplexed-readout assay that uses } \\
\text { HepG2, a human liver cell line, with measurements taken } \\
\text { at } 24 \mathrm{~h} \text { after chemical dosing in a } 24 \text {-well plate }\end{array}$ \\
\hline $\operatorname{LXR} \beta$ & 1P8D; 3KFC & $6 \mathrm{~S} 4 \mathrm{U} ; 6 \mathrm{~S} 4 \mathrm{~N}$ & 102 & 3226 & $\begin{array}{l}\text { Cell-based assay, multiplexed-readout assay that uses } \\
\text { HepG2, a human liver cell line, with measurements taken } \\
\text { at } 24 \mathrm{~h} \text { after chemical dosing in a } 24 \text {-well plate }\end{array}$ \\
\hline
\end{tabular}

$A R$ androgen receptor, $G R$ glucocorticoid receptor, $P R$ progesterone receptor, ER $\alpha$ estrogen receptor alpha, ER $\beta$ estrogen receptor beta, $P P A R \alpha$ peroxisome proliferator-activated receptor alpha, $P P A R \gamma$ peroxisome proliferator-activated receptor gamma, $R A R \alpha$ retinoic acid receptor alpha, $R O R \gamma$ retinoid-related orphan receptor-gamma, $V D R$ vitamin $\mathrm{D}$ receptor, $R X R \alpha$ retinoic $\mathrm{X}$-receptor alpha

*For AR, PDB ID 2PIW was used for docking at alternative binding pocket 1 (ABP1), for other proteins another alternative pocket was extrapolated based on AR allosteric site

${ }^{\#}$ For ROR $\gamma$, PDB ID 5C4T was used for docking at alternative binding pocket 2 (ABP2), for other proteins an alternative pocket was extrapolated based on ROR $\gamma$ allosteric site 
SMILES (Simplified molecular-input line-entry system), and chemicals with less than 5 non-hydrogen atoms.

\section{Protein structure database}

The X-ray structures of the 12 NRs used in this benchmarking study were retrieved from the RCSB PDB database (Table 1) (https://www.rcsb.org/). For each NR, two agonistbound structures and two antagonist-bound structures with high resolution were selected. In addition, we included one more AR structure (PDB ID: 2PIW) and one more ROR $\gamma$ structure (PDB ID: 5C4T), each containing a ligand bound to a unique alternative binding pocket (ABP1 and ABP2, respectively). The best resolution crystal structure was used for the remaining NRs to extrapolate the AR and ROR $\gamma$ alternative binding sites.

\section{Fatty acid prediction database}

The fatty acid (FA) library is curated from various sources such as lipidbank (https://lipidbank.jp/), seed oil fatty acid database (SOFA), (Matthäus 2012) and lipidHome (Foster et al. 2013). The fatty acids can be categorized into 10 groups, based on their chemical structures, including saturated, unsaturated, branched, hydroxy, keto, thia, epoxy, cyclopropane, acetylenic and furanoid fatty acids. Their chain lengths range from medium (C6-C12), long (C13-C21), to very long (C22 and above). The majority of fatty acids occur naturally in the diet and in the body. For each of the 252 fatty acids, the name, the number of carbon atoms, and dietary source are summarized in Table S1.

\section{Molecular docking}

All the protein structures were preprocessed by the protein preparation wizard module (Protein Preparation Wizard, Schrödinger, LLC, NewYork, NY). The 3D structures for all the ToxCast chemicals and fatty acids were prepared using LigPrep (LigPrep, Schrödinger, LLC, New York, NY). Then molecular docking was performed using the Glide module (Glide, Schrödinger, LLC, New York, NY). Firstly, to set up receptor grid, the Receptor Grid Generation Panel within the Glide suite was used to define one cubic grid box $(15 \AA$ per side) as the inner-box and another cubic box ( $20 \AA$ per side) as the outer-box, both centering at the centroid of the crystal ligand. The OPLS3e force field was employed for identifying and ranking the docking poses.

\section{Chemical similarity-weighted scoring scheme}

Known ligands of the 12 NRs were extracted from ChEMBL (https://www.ebi.ac.uk/chemb1/), using a filter that binding affinity value (Ki, Kd, EC50 and IC50) was less than
$100 \mu \mathrm{M}$. The linear fingerprints (daylight method) of the ToxCast chemicals and extracted ChEMBL ligands of the 12 NRs were generated and compared using canvas module (Canvas, Schrödinger, LLC, New York, NY) yielding the Tanimoto coefficient (Tc) metrics. For each ToxCast chemical included for one specific NR, multiple Tc values were generated with respect to various ligands of that NR, and the highest Tc value was used for that chemical. The chemical similarity-weighted scoring scheme was constructed by applying conditional weighting factor to the docking score of a chemical based on its Tc value, as stated in Eq. 1 (Fig. 1).

$$
\mathrm{E}_{\text {DOCK }}^{\prime}=(1+\mathrm{i})^{*} \mathrm{E}_{\text {DOCK }}\left\{\begin{array}{l}
i=0.25 \quad \text { if } T c>0.7 \\
i=0.10 \text { if } 0.3 \leq T c \leq 0.7 . \\
i=0 \quad \text { if } T c<0.3
\end{array}\right.
$$

\section{Evaluation of virtual screening results}

The accuracy of the virtual screening was assessed using enrichment factor (EF) and logarithmic area under curve ( $\log$ AUC), as described in Eqs. 2 and 3 (Fan et al. 2009, 2012; Mysinger and Shoichet 2010; Mysinger et al. 2012; Lim et al. 2018). The EF is the concentration of the true positives among the top-scoring docking hits compared to their concentration throughout the entire database:

EFsubset $=\frac{\left(\text { Active }_{\text {selected }} / N_{\text {subset }}\right)}{\left(\text { Active }_{\text {total }} / N_{\text {total }}\right)}$.

In this study, $\mathrm{EF}_{1}$ (enrichment factor at $1 \%$ of the ranked database) was measured. To quantify the enrichment independently of the arbitrary value of $N_{\text {subset }}$, we also calculated the area under the enrichment curve with $x$-axis on a logarithmic scale to favor early enrichment (logAUC):

$\log$ AUC $=\frac{1}{\log _{10} 100 / 0.1} \sum_{0.1}^{100} \frac{\operatorname{Active~}_{\text {selected }}(x)}{\text { Active }_{\text {total }}} \Delta x$ and $x=\log _{10} \frac{N_{\text {subset }}}{N_{\text {total }}}$,

where $\Delta x$ is 0.1 . A random selection of true positives from the database will yield a $\log$ AUC value of 14.5 while a mediocre selection picking twice as many ToxCast actives than random yields a $\log \mathrm{AUC}$ value of 24.5. Both $\mathrm{EF}_{1}$ and $\log$ AUC were considered significantly different, when one value is over $10 \%$ larger (better) or smaller (worse) than the other, otherwise these two values are considered to be comparable.

For each NR, both $\mathrm{EF}_{1}$ and $\log \mathrm{AUC}$ were computed for each receptor structure, as well as consensus over multiple receptor structures. The consensus score was calculated by ranking each compound in the database using its best energy 


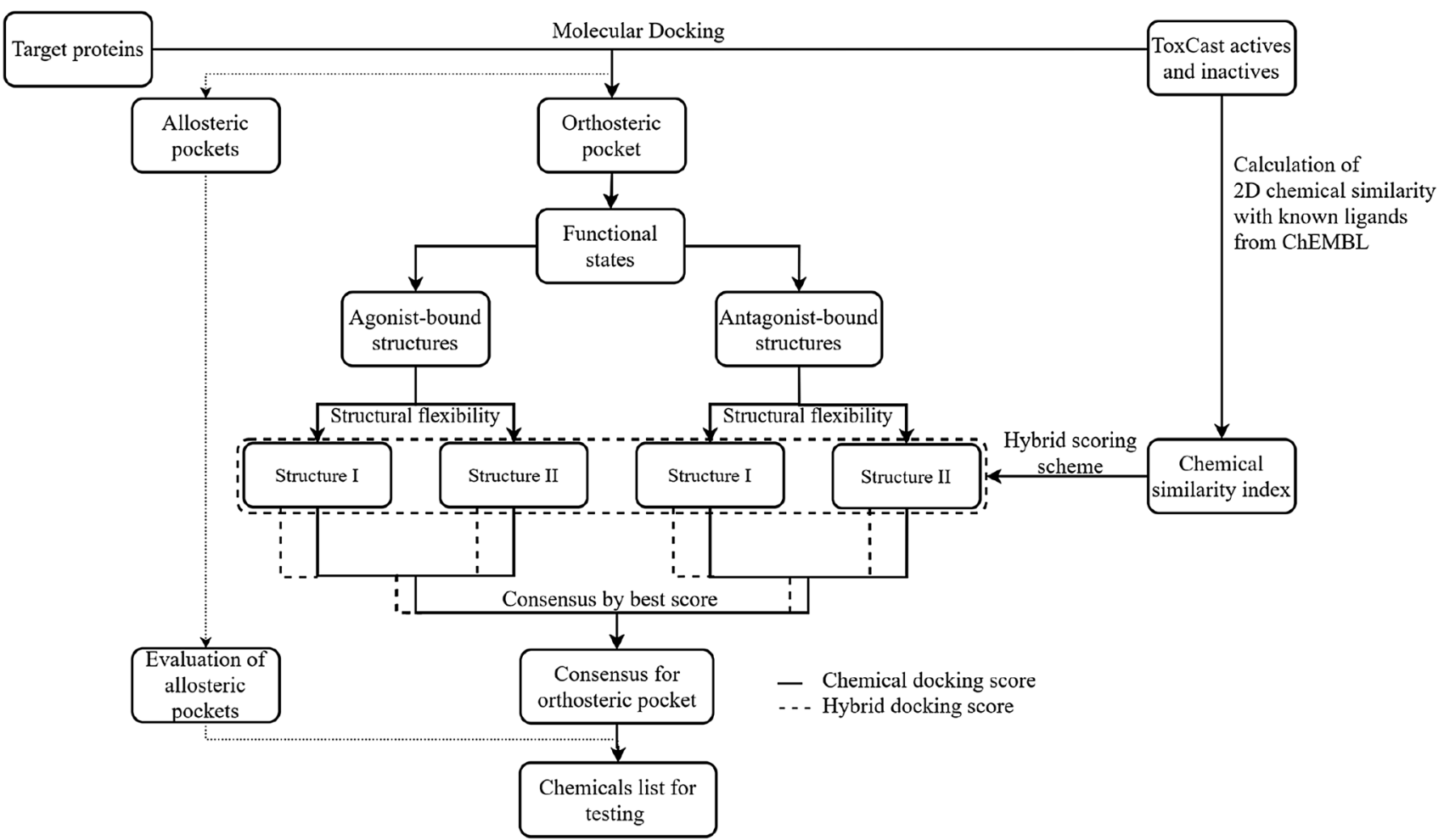

Fig. 1 Work-flow of in silico toxicity prediction targeting nuclear receptors

across all receptor structures (Fan et al. 2009; Lim et al. 2018).

\section{Experimental assays}

\section{Protein expression and purification}

PPAR $\gamma$ ligand binding domain (204-477) was cloned into pGEX-6p-1 vector (GE Healthcare) and expressed as GST fusion protein in E. Coli-BL21(DE3) strain (Agilent Technologies). The protein was firstly purified using a glutathione Sephararose 4B column, followed by PreScission protease cleavage to remove the GST-tag. The cleaved fusion protein was further purified to homogeneity by desalting, glutathione Sephararose 4B and Supperdex 75 (GE Healthcare) columns. The finally collected protein in $20 \mathrm{mM}$ Tirs, $\mathrm{pH} 8.0$, $150 \mathrm{mM} \mathrm{NaCl}$ and $2 \mathrm{mM}$ DTT was concentrated to $20 \mathrm{mg} /$ $\mathrm{ml}$. The purity was checked by SDS-PAGE and protein was stored at $-80{ }^{\circ} \mathrm{C}$ for use.

\section{Surface plasmon resonance (SPR) analysis}

PPAR $\gamma(0.05 \mathrm{mg} / \mathrm{ml})$ were coupled onto CM5 sensor chips according to amine coupling procedure from the manufacturer's manual. The final immobilization level of PPAR $\gamma$ was about 6500 resonance units (RUs). A reference channel was generated at same conditions without protein injection and used as a blank control to correct the instrument or buffer artifacts. Fatty acids were dissolved in DMSO and diluted with concentration ranging from 0.78 to $50 \mu \mathrm{M}$, and injected at a flowrate of $40 \mu \mathrm{L} / \mathrm{min}$. Each sensorgram consists of an association phase (120 s), indicating the binding of the injected compound to the protein, followed by a dissociation phase $(300 \mathrm{~s})$ during which the running buffer $(10 \mathrm{mM}$ phosphate buffer, $150 \mathrm{mM} \mathrm{NaCl}, 5 \%$ DMSO, $0.05 \%$ Tween $20, \mathrm{pH} 7.4$ ) is passed over and the bound compounds were eluted from the chip surface. The Kd was calculated by steady-state binding fitting method in Biacore T200 evaluate the software.

\section{Results and discussion}

\section{Cognate ligand docking}

To evaluate the accuracy of the docking method, we first docked the cognate ligands (ligands that bind to proteins in crystal structures) back into respective crystal structures of each target. Root mean square deviation (RMSD) was calculated between the ligand docking pose and its crystal structure. The RMSD values are shown in Table S2. We found that the current docking method reproduced the ligand 
crystal structures accurately (RMSD $<2.0 \AA$ in 49 out of 50 structures, $\mathrm{RMSD}<2.5 \AA$ in all 50 structures).

\section{Virtual screening and ToxCast active enrichment}

NRs are a family of ligand-regulated transcription factors, whose activities are mediated by a number of extracellular lipophilic ligands, including many key steroid hormones and metabolites in the endocrine systems. These receptors also exist in two distinct functional states: agonist-bound (active) state and antagonist-bound (inactive) state. We docked ToxCast actives and inactives to both functional states of the $12 \mathrm{NRs}$ in this study, considering two NR structures for each functional state (in total 48 structures, Table 1). First, we assessed the ToxCast active enrichment measured by EF1 and $\log$ AUC, from docking against a single receptor structure (Table 2). All the docking screens outperformed the random selection, with 55\% structures outperformed the mediocre selection (twice better than random). For example, two known EDCs, Bisphenol A (BPA) and Diallyl phthalate (DAP), are ranked 63 and 254, respectively, out of 1770 chemicals against ER; and are ranked 173 and 128 out of 1768 chemicals against PPAR $\gamma$ in best-performing structures, respectively.

\section{Consensus over multiple receptor structures}

In virtual screening against single structures, the structural flexibility of the protein target and associated ligand selectivity are often not fully considered. To better take this into account, for each of $12 \mathrm{NRs}$, we included two active structures and two inactive structures. The consensus enrichments from 2 structures of each functional state and from 4 structures of two functional states were calculated separately.

Table 2 ToxCast active enrichment from every single structure, and the consensus over multiple structures

\begin{tabular}{|c|c|c|c|c|c|c|c|}
\hline \multirow[t]{2}{*}{ Receptor } & \multicolumn{3}{|c|}{ Active structures } & \multicolumn{3}{|c|}{ Inactive structures } & \multirow{2}{*}{$\begin{array}{l}\text { Total consen- } \\
\text { sus logAUC } \\
(\mathrm{EF} 1)\end{array}$} \\
\hline & PDB ID & $\log \mathrm{AUC}(\mathrm{EF} 1)$ & $\begin{array}{l}\text { Concensus } \\
\log A U C(E F 1)\end{array}$ & PDB ID & $\log \mathrm{AUC}(\mathrm{EF} 1)$ & $\begin{array}{l}\text { Consensus } \\
\log \mathrm{AUC}(\mathrm{EF} 1)\end{array}$ & \\
\hline \multirow[t]{2}{*}{ AR } & $3 \mathrm{~L} 3 \mathrm{X}$ & $35.3(9.4)$ & $35.5(\mathbf{1 1 . 5})$ & 3RLJ & $24.8(0.0)$ & $24.8(3.1)$ & $27.9(\mathbf{1 1 . 5})$ \\
\hline & $2 \mathrm{AX} 9$ & $28.4(5.2)$ & & $20 Z 7$ & $25.5(3.1)$ & & \\
\hline \multirow[t]{2}{*}{ GR } & $3 \mathrm{~K} 22$ & $29.3(7.6)$ & $28.3(4.7)$ & $1 \mathrm{NHZ}$ & $29.5(9.4)$ & $29.6(4.7)$ & $32.5(9.4)$ \\
\hline & 6EL9 & $28.3(4.7)$ & & $4 \mathrm{MDD}$ & $24.3(3.5)$ & & \\
\hline \multirow[t]{2}{*}{ PR } & 1SQN & $31.1(15.8)$ & $\mathbf{3 4 . 0}(13.0)$ & $2 \mathrm{OVH}$ & $35.6(8.8)$ & $39.2(10.6)$ & $\mathbf{4 0 . 0}(13.0)$ \\
\hline & $3 \mathrm{KBA}$ & $30.8(8.8)$ & & 4OAR & $32.9(8.8)$ & & \\
\hline \multirow[t]{2}{*}{$\mathrm{ER} \alpha$} & $1 \mathrm{X} 7 \mathrm{R}$ & $32.9(11.6)$ & $31.0(7.6)$ & $1 \mathrm{XP} 1$ & $31.7(12.6)$ & $33.5(10.1)$ & $33.5(12.6)$ \\
\hline & $5 \mathrm{U} 2 \mathrm{D}$ & $28.2(8.4)$ & & $2 \mathrm{IOK}$ & $30.2(5.9)$ & & \\
\hline \multirow[t]{2}{*}{$\mathrm{ER} \beta$} & 3OLL & $28.2(8.1)$ & $31.7(9.2)$ & 1L2J & $31.0(11.7)$ & $34.2(12.7)$ & $34.5(11.7)$ \\
\hline & $1 \mathrm{U} 3 \mathrm{R}$ & $28.4(8.1)$ & & $1 \mathrm{NDE}$ & $31.1(8.1)$ & & \\
\hline \multirow[t]{2}{*}{$\operatorname{PPAR} \alpha$} & $2 \mathrm{P} 54$ & $21.2(7.9)$ & $27.8(7.9)$ & $1 \mathrm{KKQ}$ & $29.6(5.3)$ & $29.6(5.3)$ & $30.1(7.9)$ \\
\hline & $1 \mathrm{I} 7 \mathrm{G}$ & $27.4(7.9)$ & & 2REW & $26.6(5.3)$ & & \\
\hline \multirow[t]{2}{*}{$\operatorname{PPAR} \gamma$} & $3 \mathrm{BC} 5$ & $20.9(2.8)$ & $21.0(3.7)$ & 5DWL & $20.4(2.8)$ & $22.1(4.4)$ & $23.6(4.8)$ \\
\hline & $3 \mathrm{VSO}$ & $18.2(3.7)$ & & $5 \mathrm{LSG}$ & $21.0(4.6)$ & & \\
\hline \multirow[t]{2}{*}{$\operatorname{RAR} \alpha$} & 3KMR & $20.3(0.0)$ & $21.4(\mathbf{2 . 4})$ & $1 \mathrm{DKF}$ & $21.8(2.4)$ & $23.5(2.4)$ & $23.0(2.4)$ \\
\hline & $3 \mathrm{~A} 9 \mathrm{E}$ & $24.0(0.0)$ & & $5 \mathrm{~K} 13$ & $25.1(2.4)$ & & \\
\hline \multirow[t]{2}{*}{$\mathrm{ROR} \gamma$} & $3 \mathrm{LOL}$ & $20.1(2.4)$ & $20.8(3.6)$ & $5 \mathrm{NTK}$ & $20.7(1.2)$ & 21.7 (1.9) & 23.9 (3.6) \\
\hline & 4WLB & $21.0(3.6)$ & & $5 \mathrm{~K} 3 \mathrm{~N}$ & $21.4(1.2)$ & & \\
\hline \multirow[t]{2}{*}{ VDR } & 3В0T & $21.3(1.8)$ & $23.8(\mathbf{2 . 5})$ & $5 \mathrm{XPL}$ & $20.4(2.0)$ & $21.3(\mathbf{2 . 4})$ & $22.9(\mathbf{2 . 5})$ \\
\hline & $3 \mathrm{AZ2}$ & $21.7(2.2)$ & & 5XUQ & $19.8(1.4)$ & & \\
\hline \multirow[t]{2}{*}{$\mathrm{RXR} \alpha$} & $1 \mathrm{MVC}$ & $20.7(4.6)$ & 24.1 & $3 \mathrm{NSQ}$ & $20.1(3.1)$ & $27.6(7.7)$ & $\mathbf{2 8 . 0}(9.2)$ \\
\hline & $5 \mathrm{LYQ}$ & $21.5(3.1)$ & & $2 \mathrm{P} 1 \mathrm{~V}$ & $24.2(9.2)$ & & \\
\hline \multirow[t]{2}{*}{$\operatorname{LXR} \beta$} & 1P8D & $18.9(3.1)$ & $21.3(5.2)$ & $6 \mathrm{~S} 4 \mathrm{U}$ & $18.2(1.0)$ & $21.2(4.2)$ & $21.9(5.2)$ \\
\hline & $3 \mathrm{KFC}$ & $18.8(4.2)$ & & $6 \mathrm{~S} 4 \mathrm{~N}$ & $19.0(2.1)$ & & \\
\hline
\end{tabular}

Consensus $\log \mathrm{AUC} / \mathrm{EF} 1, \log \mathrm{AUC} / \mathrm{EF} 1$ calculated from consensus docking scores from two structures of a single functional state (active or inactive state). Total consensus $\log \mathrm{AUC} / \mathrm{EF} 1, \log \mathrm{AUC} / \mathrm{EF} 1$ calculated from consensus docking scores from four structures ( 2 active and 2 inactive structures.) Consensus logAUC/EF1 (and Total consensus logAUC/EF1) is in bold/italic font when it is $10 \%$ larger/smaller than that from the best performing structure, and in a normal font in rest cases where it is considered to be comparable 


\section{Single functional state}

First, for each NR, we compared the consensus enrichment (logAUC and EF1) over 2 receptor structures of a single functional state (either active or inactive) and the corresponding enrichments from single structure screening. Out of the 24 functional states of 12 NRs, consensus logAUC values are better, comparable to, and worse than that from the better performing structure in $33.3 \%, 62.5 \%$, and $4.2 \%$ of cases, respectively; similarly, consensus EF1 values are better, comparable to, and worse than that from the best performing structure in $37.5 \%, 37.5 \%$ and $25.0 \%$ cases, respectively (Table 2). We note that the consensus enrichment values (both $\log \mathrm{AUC}$ and EF1) in each of these worse cases, are still better than or comparable to that from the other structure in the same functional state.

\section{Dual functional states}

Second, for each NR, we calculated the total consensus enrichment (logAUC and EF1) over 4 receptor structures of both functional states. Out of $12 \mathrm{NRs}$, total consensus $\log$ AUC values are better than, comparable to, and worse than that from the best performing structure in $58.3 \%$, $33.3 \%$, and $8.3 \%$ of cases, respectively; similarly, total consensus EF1 values are better, comparable to, and worse than that from the best performing structure in $25.0 \%, 66.7 \%$ and $8.3 \%$ cases, respectively (Table 2 ; Fig. 2 ). We note that the total consensus enrichment values (both $\log \mathrm{AUC}$ and EF1) in each of these worse cases are still better than or comparable to that from the second-best performing structure of that NR. When the consensus score over multiple structures was applied, the ranks of known EDCs were often improved in comparison to that from the best performing structure. For example, the rank of BPA against ER $\alpha$ and PPAR $\gamma$ has improved from 63 and 173 (the best performing structures) to 29 and 64, respectively; while the rank for DAP against $\mathrm{ER} \alpha$ and PPAR $\gamma$ has improved from 254 and 128 to 88 and 67 , respectively.

\section{ToxCast active selectivity by different functional states}

To further understand whether docking against active or inactive structures confers any selectivity or not, we examined the docking screens in detail. Significant differences $(10 \%)$ between consensus logAUC values from active and inactive structures were observed in $\mathrm{AR}, \mathrm{PR}, \mathrm{RXR} \alpha$, and RAR $\alpha$. In PR, RXR $\alpha$, and RAR $\alpha$, inactive structures yielded higher consensus $\log \mathrm{AUC}$ values than active structures; while in AR, it is the opposite- the consensus $\log A U C$ value from active structures (35.5) is higher than that from inactive structures (24.8). In AR and RXR $\alpha$, we also observed a similar trend in consensus EF1 as their consensus logAUC.
In AR, The significant differences in $\log \mathrm{AUC}$ and $\mathrm{EF} 1$ are due to the fact that among ToxCast actives of AR, 38\% of these ToxCast actives are known AR agonists (Kleinstreuer et al. 2017; Lynch et al. 2017). These observations suggest possible selectivity of ToxCast actives by active or inactive structures of these receptors. For instance, the ToxCast active tetrahydroxybenzophenone was ranked 14 in one active structure of AR (PDB ID: 3L3X, Fig. 3a) but only 669 in one inactive structure of the same receptor (PDB ID: 2OZ7). In contrast, the ToxCast active triconazole, was ranked 1565 and 4 in these two AR structures, respectively (Fig. 3b). We presume that these opposite trends may be due to conformational changes in TRP741, MET745, and MET895. In that active structure, these residues are stacked against each other, resulting in a smaller binding site that favors tetrahydroxybenzophenone over triconazole. Compared to their orientations in that active structure, these residues are further away from each other in that inactive structure, resulting in a larger binding site that favors triconazole over tetrahydroxybenzophenone.

These results on consensus ToxCast active enrichment are very promising, as simply by taking the consensus it will very likely approach the potential EDC recognition ability of the best or second-best performing structure that would often be difficult to know in advance in real applications. This could be because different structures of each receptor complement different groups of ToxCast actives but not the inactives so that a consensus selection relying on the best docking score of each chemical derived using multiple receptor structures from two functional states could rescue certain potential EDCs that would be missed by a single receptor structure.

\section{Hybrid scoring scheme}

\section{Enrichment based on chemical similarity index}

In this study, we also performed virtual screening of 12 targets using the chemical similarity index (Tc, 2D fingerprints) of the chemicals with known binders (extracted from ChEMBL). We generated the Tc values with known binders from ChEMBL as mentioned in the methods section, then calculated their $\log$ AUC values based only on Tc values. The consensus $\log$ AUC values from 4 receptor structures using only Tc values of chemicals are worse than those using docking scores in 11 out of 12 NRs (91.6\%), only comparable in the case of PR (Fig. 4). The performance of virtual screening using only Tc values, however, still yielded consensus enrichment better than random selection in 10 NRs. Since ligand-based (chemical similarity) and structure-based (docking) approaches are not completely correlated and both methods have reasonable enrichment potential (Ewing et al. 2006; Sastry et al. 2010; Kortagere et al. 2010; Huang et al. 

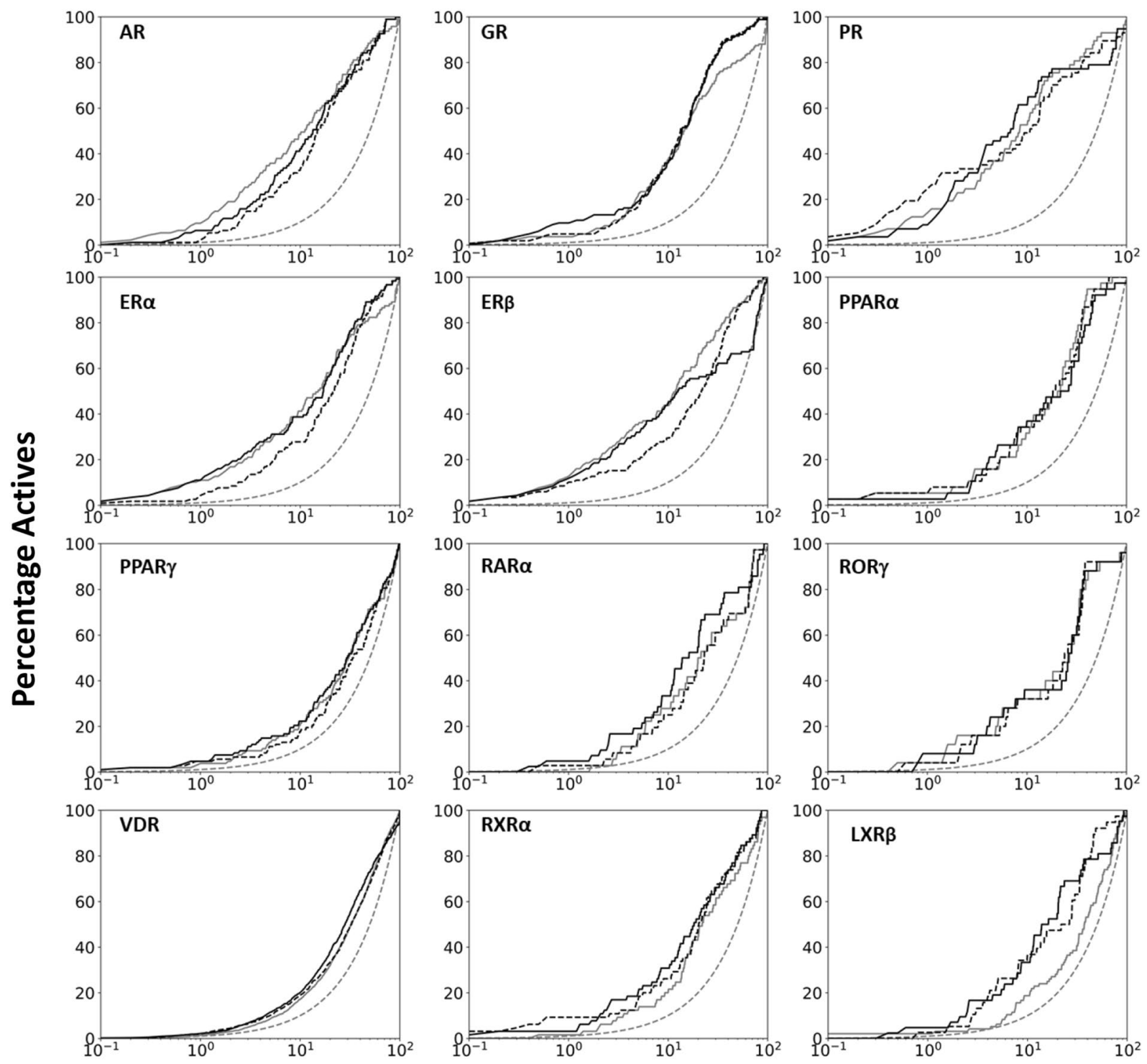

\section{Percentage database}

Fig. 2 ToxCast active enrichment plots for 12 nuclear receptors, including random selection as reference (dotted line, grey), the enrichment from the best performing structure of each NR (solid

2016; Cleves and Jain 2020), we explored an arbitrary combination of both approaches to enhance the overall enrichment. The assumption is that the respective errors in their enrichment are somewhat unlinked and that the integrated method may have a synergistic advantage.

\section{Chemical similarity-weighted scoring scheme}

To combine both chemical similarity and docking approaches, we implemented a hybrid scoring scheme (Eq. 1), resulting in a new score $\left(E^{\prime}{ }_{\text {DOCK }}\right)$ for each chemical. With our hybrid scoring scheme, improved and comparable line, grey), the consensus enrichment over 4 structures (2 active and 2 inactive structures) with $E_{\mathrm{DOCK}}$ (dotted line, black) and with $E_{\text {DOCK }}$ (solid line, black)

$\log$ AUC values are observed in $39.6 \%$ and $60.4 \%$ of screening against the 48 structures used for the $12 \mathrm{NRs}$, with respect to those using original docking scores $\left(E_{\mathrm{DOCK}}\right)$ (Table 3). For early enrichment (EF1), the hybrid scoring scheme led to an improvement in more cases (64.6\%) and the rest remain comparable. Out of the 24 functional states of $12 \mathrm{NRs}$, the consensus logAUC of single functional state with $E_{\text {DOCK }}$ are better than and comparable to the $\log$ AUC with $E_{\text {DOCK }}$ from the more enriching structure in $29.2 \%$ and $70.8 \%$ of cases, respectively, while better than and comparable to the consensus $\log$ AUC of single functional state with $E_{\mathrm{DOCK}}$ in $25.0 \%$ and $75.0 \%$ of cases, respectively. Similarly, 
Fig. 3 a Tetrahydroxybenzophenone docked in the active structure of AR (PDB ID 3L3X), b Triticonazole docked in the inactive structure of AR (PDB ID 2OZ7), c Nilutamide in PR (PDB ID: 1SQN), docking rank enhanced to 49 from 292 after applying the hybrid scoring scheme, $\mathbf{d}$ Esfenvalerate in GR (PDB ID: 4MDD), docking rank enhanced to 16 from 117 after applying the hybrid scoring scheme, e Morin, docked at alternate binding pocket 1 (ABP1) of PPARa (PDB ID: 2P54), f 5HPP-33, docked at alternate binding pocket 2 (ABP2) of ROR $\gamma$ (PDB ID: $5 \mathrm{C} 4 \mathrm{~T})$

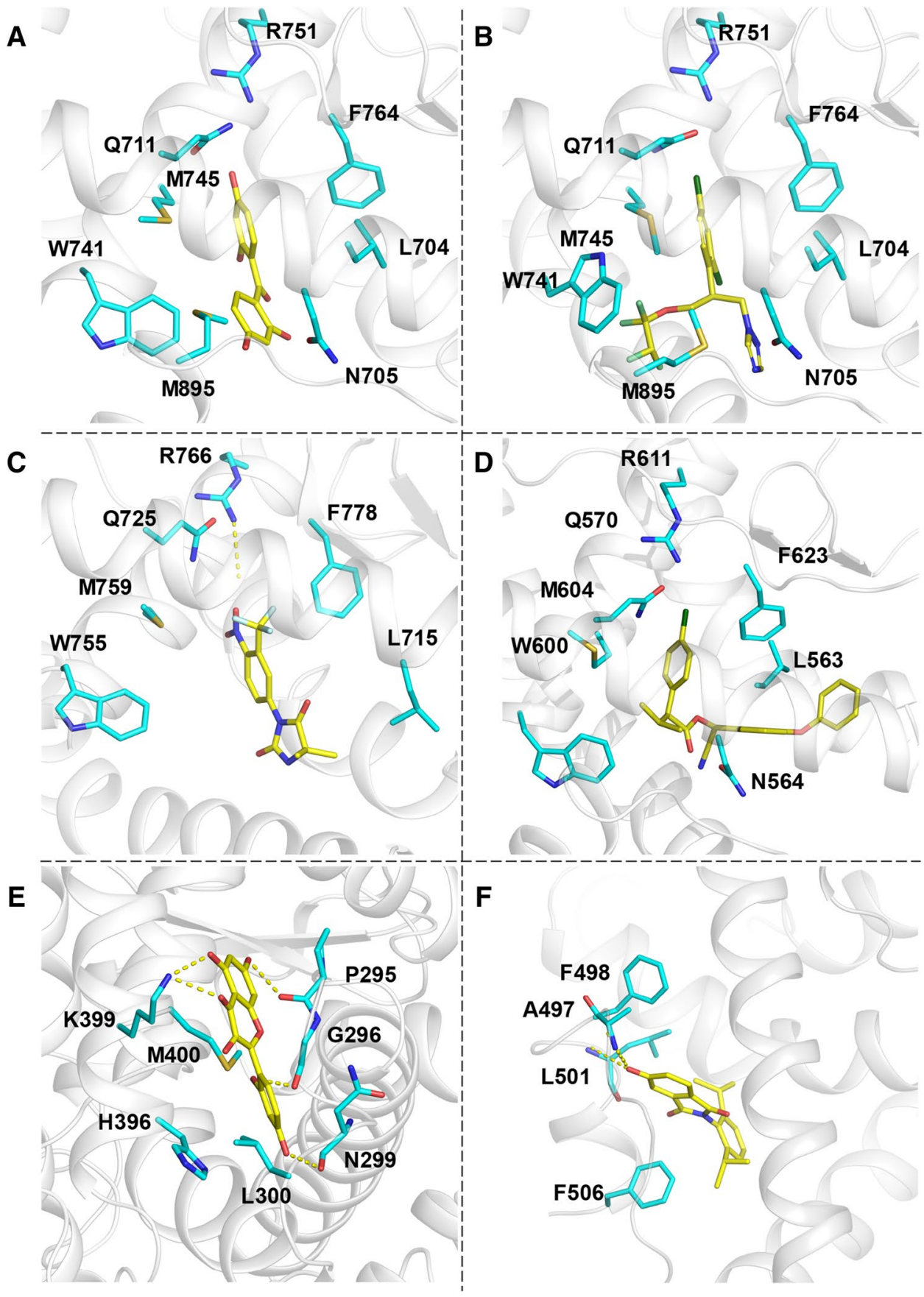

the consensus EF1 of single functional state with $E^{\prime}{ }_{\text {DOCK }}$ are better than, comparable to, and worse than the EF1 with $E^{\prime}{ }_{\text {DOCK }}$ from the more enriching structure in $25.0 \%, 41.7 \%$, and $33.3 \%$ of cases, respectively, while better than and comparable to the consensus EF1 of single functional state with $E_{\mathrm{DOCK}}$ in $62.5 \%$ and $37.5 \%$ of cases, respectively. Considering all 4 receptor structures together, the total consensus $\log$ AUC with $E_{\text {DOCK }}$ are better than and comparable to the $\log$ AUC from the most enriching structure with $E^{\prime}{ }_{\text {DOCK }}$ in $33.3 \%$ and $66.7 \%$ of cases, respectively, while better than and comparable to the total consensus $\log \mathrm{AUC}$ with $E_{\mathrm{DOCK}}$ in $8.3 \%$ and $91.7 \%$ of cases, respectively. Similarly, the total consensus EF1 with $E_{\text {DOCK }}$ are better than, comparable to, and worse than the EF1 with $E$ ' ${ }_{\text {DOCK }}$ from the most enriching structure in $25.0 \%, 33.3 \%$, and $41.7 \%$ of cases, respectively, while better than, comparable to, and worse than the total consensus EF1 with $E_{\mathrm{DOCK}}$ in $50.0 \%, 33.3 \%$, and $16.7 \%$ of cases, respectively.

These comparisons between results from $E_{\text {DOCK }}$ and $E_{\mathrm{DOCK}}$ indicate that we can expect improved overall enrichment (logAUC) and more commonly improved early enrichment (EF1), without detrimental effects on 
Fig. 4 Comparison between ToxCast actives enrichment $(\log$ AUC) of chemical similarity-based screening (orange), consensus enrichment over 4 structures ( 2 active and 2 inactive structures) with $E_{\mathrm{DOCK}}$ (blue) and with $E_{\text {DOCK }}$ (grey)

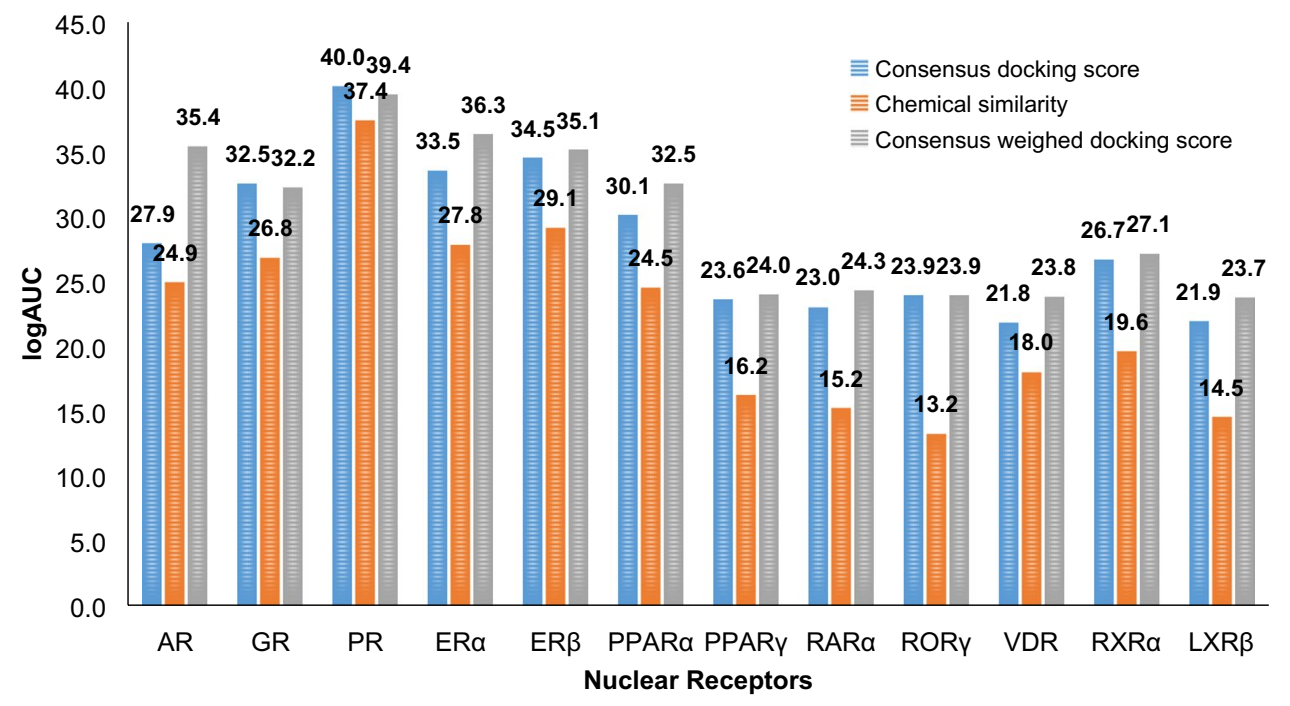

Table 3 ToxCast active enrichment generated using the hybrid scoring scheme

\begin{tabular}{|c|c|c|c|c|c|c|c|}
\hline \multirow{2}{*}{ Receptor } & \multicolumn{3}{|c|}{ Active structures } & \multicolumn{3}{|c|}{ Inactive structures } & \multirow{2}{*}{$\begin{array}{c}\text { Total consensus } \\
\text { logAUC (EF1) }\end{array}$} \\
\hline & PDB ID & logAUC (EF1) & Concensus logAUC (EF1) & PDB ID & logAUC (EF1) & Consensus logAUC (EF1) & \\
\hline$\overline{\mathrm{AR}}$ & $\begin{array}{l}\text { 3L3X } \\
2 A X 9\end{array}$ & $\begin{array}{r}35.4(11.5) \\
28.9(5.2)\end{array}$ & $32.3(11.5)$ & $\begin{array}{l}\text { 3RLJ } \\
2 \mathrm{OZ7}\end{array}$ & $\frac{28.1}{26.8}\left(\frac{1.0}{(3.1)}\right)$ & $\underline{27.5}(\underline{4.2})$ & $\underline{35.4}(11.5)$ \\
\hline GR & $\begin{array}{l}3 \mathrm{~K} 22 \\
6 \mathrm{EL} 9\end{array}$ & $\begin{array}{l}29.8(12.9) \\
29.0(11.1)\end{array}$ & $29.1(\underline{9.4})$ & $\begin{array}{l}1 \mathrm{NHZ} \\
4 \mathrm{MDD}\end{array}$ & $\begin{array}{r}29.8(11.7) \\
25.2(\underline{5.9})\end{array}$ & $29.9(\underline{6.4})$ & $32.2(9.4)$ \\
\hline PR & $\begin{array}{l}1 S Q N \\
3 K B A\end{array}$ & $\frac{34.1}{35.0} \frac{(28.1)}{(29.8)}$ & $37.3(\underline{27.8})$ & $\begin{array}{l}2 \mathrm{OVH} \\
4 \mathrm{OAR}\end{array}$ & $\left.\frac{41.1}{36.7} \frac{(28.1}{(24.6}\right)$ & $39.4(\underline{24.3})$ & $39.4(\underline{24.8})$ \\
\hline ERa & $\begin{array}{l}1 \mathrm{X} 7 \mathrm{R} \\
5 \mathrm{U} 2 \mathrm{D}\end{array}$ & $\frac{36.7}{34.2}\left(\frac{19.3}{15.2}\right)$ & $\underline{36.0}(\underline{12.6})$ & $\begin{array}{l}1 \mathrm{XP1} \\
2 \mathrm{IOK}\end{array}$ & $\begin{array}{l}31.8(21.9) \\
33.2(18.5)\end{array}$ & $36.4(\underline{12.6})$ & $36.3(\underline{18.5})$ \\
\hline $\mathrm{ER} \beta$ & $\begin{array}{l}3 \mathrm{OLL} \\
1 \mathrm{U} 3 \mathrm{R}\end{array}$ & $\frac{32.7}{33.2}\left(\frac{15.2}{16.5}\right)$ & $33.0(16.5)$ & $\begin{array}{r}1 \mathrm{~L} 2 \mathrm{~J} \\
1 \mathrm{NDE}\end{array}$ & $\frac{34.8}{35.0}\left(\frac{17.9}{17.9}\right)$ & $35.0(12.7)$ & $35.1(\underline{17.9})$ \\
\hline PPARa & $\begin{array}{c}2 \mathrm{P} 54 \\
117 \mathrm{G}\end{array}$ & $\begin{array}{l}23.1(7.9) \\
27.2(7.9)\end{array}$ & $30.4(7.9)$ & $\begin{array}{l}1 \mathrm{KKQ} \\
2 \mathrm{REW}\end{array}$ & $\begin{array}{l}27.7(5.3) \\
28.4(5.3)\end{array}$ & $27.8(5.3)$ & $32.5(5.3)$ \\
\hline PPARY & $\begin{array}{l}3 \mathrm{BC5} \\
3 \mathrm{VSO}\end{array}$ & $\begin{array}{l}20.0(2.8) \\
18.3(3.7)\end{array}$ & $22.1(\underline{4.6})$ & $\begin{array}{l}5 \mathrm{DWL} \\
5 \mathrm{LSG}\end{array}$ & $\begin{array}{l}21.0(\underline{3.7}) \\
21.1(4.6)\end{array}$ & $23.6(4.8)$ & $24.0(4.8)$ \\
\hline RARa & $\begin{array}{l}3 \mathrm{KMR} \\
3 \mathrm{~A} 9 \mathrm{E}\end{array}$ & $\begin{array}{l}20.3(0.0) \\
24.1(2.4)\end{array}$ & $\underline{24.2}(\underline{5.6})$ & $\begin{array}{l}1 \mathrm{DKF} \\
5 \mathrm{~K} 13\end{array}$ & $\begin{array}{l}22.5(2.4) \\
24.0(2.4)\end{array}$ & $24.7(\underline{8.3})$ & $24.3(\underline{5.6})$ \\
\hline RORY & $\begin{array}{c}3 \mathrm{LOL} \\
4 \mathrm{WLB}\end{array}$ & $\begin{array}{l}21.5(3.6) \\
22.9(4.8)\end{array}$ & $22.6(\underline{4.8})$ & $\begin{array}{l}5 \mathrm{NTK} \\
5 \mathrm{~K} 3 \mathrm{~N}\end{array}$ & $\begin{array}{l}22.1(2.4) \\
23.4(2.4)\end{array}$ & $\underline{24.2}(1.8)$ & $23.1(\underline{4.8})$ \\
\hline VDR & $\begin{array}{l}3 \mathrm{~B} 0 \mathrm{~T} \\
3 \mathrm{AZ2}\end{array}$ & $\begin{array}{l}21.4(1.8) \\
22.0(2.2)\end{array}$ & $24.0(2.5)$ & $\begin{array}{l}5 X P L \\
5 X \cup Q\end{array}$ & $\begin{array}{l}20.9(2.0) \\
20.2(1.4)\end{array}$ & $21.8(2.1)$ & $23.7(2.5)$ \\
\hline $\mathrm{RXRa}$ & $\begin{array}{l}1 \mathrm{MVC} \\
5 \mathrm{LYQ}\end{array}$ & $\frac{23.3}{24.1} \frac{(10.8)}{(7.7)}$ & $\underline{\mathbf{2 6 . 7}}(4.6)$ & $\begin{array}{l}3 \mathrm{NSQ} \\
2 \mathrm{P} 1 \mathrm{~V}\end{array}$ & $\frac{23.8}{23.9}(\underline{10.8})$ & $27.8(\underline{9.2})$ & $27.1(4.6)$ \\
\hline LXR $\beta$ & $\begin{array}{l}\text { 1P8D } \\
3 \mathrm{KFC}\end{array}$ & $\frac{21.2}{21.3} \frac{(5.2)}{(5.2)}$ & $\underline{23.5}(\underline{6.3})$ & $\begin{array}{l}6 S 4 U \\
6 S 4 N\end{array}$ & $\frac{20.4}{21.4} \frac{(3.1)}{(5.2)}$ & $22.6(\underline{5.2})$ & $23.7(\underline{6.3})$ \\
\hline
\end{tabular}

$\log$ AUC/EF1, Consensus $\log \mathrm{AUC} / \mathrm{EF} 1$, and Total consensus $\log \mathrm{AUC} / \mathrm{EF} 1$ from the orthosteric pocket are calculated, compared, and marked in the same manner as in Table 2, except that the hybrid score $\left(\mathrm{E}^{\prime}{ }_{\mathrm{DOCK}}\right)$ is used in the calculation instead of the original docking score $\left(\mathrm{E}_{\mathrm{DOCK}}\right)$. These values are also compared to the counterparts in Table 2, and highlighted with straight or waved underline when they are better or worse than the counterparts in Table 2

Consensus $\log \mathrm{AUC} / \mathrm{EF} 1$ (and Total consensus $\log \mathrm{AUC} / \mathrm{EF} 1$ ) is in bold/italic font when it is $10 \%$ larger/smaller than that from the best performing structure, and in a normal font in rest cases where it is considered to be comparable

the rest, when the hybrid scoring scheme is applied to docking results from single structures or from a consensus over multiple structures in the same functional state. For example, in the case of PR, the $\log$ AUC with $E^{\prime}{ }_{\text {DOCK }}$ is improved by $10 \%, 14 \%, 15 \%$ and $12 \%$ in the 4 structures (PDB ID: 1SQN, 3KBA, 2OVH, and 4OAR), respectively; and the EF1 with $E^{\prime}$ DOCK was improved by $78 \%, 239 \%$, $219 \%$, and $180 \%$, respectively. These significant improvements are due to the fact that among ToxCast actives of
PR, 37\% of these ToxCast actives are chemically similar to the known ChEMBL ligands of $\mathrm{PR}(\mathrm{Tc} \geq 0.3)$, reflected by the improved ranks of these 57 chemicals with $E_{\text {DOCK }}$ (Table S3). In particular, the rank of a cancer drug Nilutamide (ToxCast active, T00001559, $\mathrm{Tc}=0.49$ ) is enhanced from 292 (with $E_{\text {DOCK }}$ ) to 49 (with $E_{\text {DOCK }}$ ) against the active structure 1SQN (Fig. 3c). In the case of GR, the $\log$ AUC of the 4 structures (PDB ID: 3K22, 6EL9, 1NHZ, and $4 \mathrm{MDD})$ are comparable to those with $E_{D O C K}$. However, 
the EF1 with $E_{\text {DOCK }}$ was improved by $70 \%, 136 \%, 24 \%$, and $68 \%$, respectively. Among ToxCast actives of GR, only $18 \%$ of these ToxCast actives are chemically similar to the known ChEMBL ligands of GR. In particular, the rank of a pyrethroid insecticide Esfenvalerate (ToxCast active, T00001302, Tc $=0.69$ ) is enhanced from 117 (with $E_{\text {DOCK }}$ ) to 16 (with $E_{\text {DOCK }}$ ) against the inactive structure 4MDD (Fig. 3d). We also investigated the performance of known EDCs, when the hybrid scoring scheme was applied to the docking results, the scores and ranks were often improved. For example, the ranks based on total consensus scores of BPA against ER $\alpha$ and PPAR $\gamma$ are improved from 29 (with $E_{\text {DOCK }}$ ) to 11 (with $E^{\prime}{ }_{\text {DOCK }}$ ) and from 64 (with $E_{\text {DOCK }}$ ) to 21 (with $E^{\prime}{ }_{\text {DOCK }}$ ), respectively; and the ranks of DAP against $\mathrm{ER} \alpha$ and PPAR $\gamma$ are improved from $88\left(E_{\mathrm{DOCK}}\right)$ to 34 (with $E_{\text {DOCK }}^{\prime}$ ) and from 67 (with $E_{\text {DOCK }}$ ) to 14 (with $E^{\prime}{ }_{\text {DOCK }}$ ), respectively.

When the total consensus $E_{\text {DOCK }}^{\prime}$ (over all the 4 structures of each NR) was applied, at least 4 and 14 ToxCast actives are detected among the top-ranked 20 ToxCast chemicals (20\% and $70 \%)$ for 10 and 5 NRs, respectively (Table S4). The numbers of ToxCast actives in the topranked 20 ToxCast chemicals using the total consensus $E^{\prime}{ }_{\text {DOCK }}$, are higher than, equal to, and lower than those using the $E_{\mathrm{DOCK}}$ from the most enriching structures in $75.0 \%, 16.7 \%$, and $8.3 \%$ of cases, respectively; while higher than, equal to, and lower than those using the total consensus $E_{\text {DOCK }}$ in $50.0 \%, 33.3 \%$, and $16.7 \%$ of cases, respectively. Considering the marginal but systematic improvement in ToxCast active enrichment, the combination of consensus over multiple structures and hybrid scoring scheme is probably the optimal method for potential EDC recognition, when both multiple receptor structures and known ligands are available for the target protein.

\section{Alternative pockets}

Our previous results emphasized the importance of using multiple structures, hybrid scoring scheme in the recognition of ToxCast actives of 12 NRs. However, these calculations were done with the assumption that these actives bind only to the orthosteric binding pocket (OBP). However, AR (Lack et al. 2011; Lallous et al. 2016) and ROR $\gamma$ (Song et al. 2016) have been previously reported to have alternate binding pockets $A B P 1$ and $A B P 2$, respectively. In $A R$, the $A B P 1$ (PDB ID: 2PIW) is also known as binding function 3 site (BF3), that is a hydrophobic site located at the junction of $\mathrm{H} 1$, the loop of $\mathrm{H} 3-5$, and $\mathrm{H} 9$, adjacent to activation function site (AF2, cofactor binding site). In ROR $\gamma$, the ABP2 (PDB ID: 5C4T) consists of H4, H5, H11 and the repositioned $\mathrm{H} 12$ in its agonistic state, adjacent to the AF2 site but distal to OBP. Ligands binding to these ABPs have been implicated in the activation/inactivation mechanism in these nuclear receptors (Lack et al. 2011; Song et al. 2016; Lallous et al. 2016). In this study, we extrapolated ABP1 of AR and $\mathrm{ABP} 2$ of $\mathrm{ROR} \gamma$ to the best resolution structure of each of the remaining $11 \mathrm{NRs}$, respectively, because both ABP conformations vary little among the 4 receptor structures of each NR used in this study. Thereafter, ToxCast actives and inactives were docked to ABP1 and ABP2 of each NR.

11 and 3 docking screens at ABP1 (confirmed in AR, predicted in the rest $11 \mathrm{NRs})$ outperformed $(\geq 10 \%)$ random and mediocore selection, respectively; while only 4 docking screens at ABP2 (confirmed in ROR $\gamma$, predicted in the rest $11 \mathrm{NRs}$ ) outperformed random selection (Table 4). In comparison to the results from OBP, docking against ABP1 in 6 NRs yielded better (PPAR $\alpha$ ) or comparable (GR, PPAR $\gamma, \mathrm{ROR} \gamma, \mathrm{VDR}, \mathrm{RXR} \alpha$ ) performance and all the rest are worse. Combining results from OBP and $\mathrm{ABP}(\mathrm{s})$ together, the consensus logAUC of OBP $+\mathrm{ABP} 1$ are better than, comparable to, and worse than that from the $\log \mathrm{AUC}$ of OBP in $25 \%, 58 \%$ and $17 \%$ of NRs, respectively; the consensus EF1 of OBP and ABP1 are better than, comparable to, and worse than that from the EF1 of OBP in 33\%, $50 \%$ and $17 \%$ of NRs, respectively. The consensus $\log$ AUC and $\mathrm{EF} 1$ of $\mathrm{OBP}+\mathrm{ABP} 1+\mathrm{ABP} 2$ presented the same performance. These results suggest that consensus over OBP and $\mathrm{ABP}(\mathrm{s})$ may in non-negligible number of cases lead to reduced accuracy in ToxCast active prediction, therefore, caution should be taken for including ABP-targeted docking screens in the prediction of potential EDCs, especially when ABPs are only predicted. In the meantime, we note that in 8 NRs more than $10 \%$ ToxCast actives received better docking scores from ABP1 than those from OBP, with the highest ratio from PPAR $\alpha$ (35\%). These 8 NRs include 5 out of the 6 NRs that showed better ToxCast active enrichment from $\mathrm{ABP} 1$ than that from $\mathrm{OBP}$, indicating $\mathrm{ABP} 1$ should be considered in chemical toxicity prediction at least for these 5 NRs (PPAR $\alpha$, GR, PPAR $\gamma$, ROR $\gamma, \mathrm{RXR} \alpha$ ). For example, in the case of PPAR $\alpha$, where the $\log$ AUC values from OBP and $\mathrm{ABP} 1$ are 21.2 and 28.5, respectively, and the consensus $\log$ AUC is enhanced to 32.6 , three ToxCast actives including econazole, morin, and apomorphine, have much better docking scores (data not shown) and ranks from ABP1 (12, 15 , and 61) than those from $\operatorname{OBP}(996,445$, and 1323), respectively. In ABP1, the docked morin formed hydrogen bond interactions with PRO295, GLY296, ASN299, and LYS399 using its hydroxy/keto groups, and pi-pi stacking interaction with HIS396 using its phenyl ring (Fig. 3e). In addition, docking screens against $\mathrm{ABP}(\mathrm{s})$ may still be beneficiary even when the enrichment values from $\mathrm{ABP}(\mathrm{s})$ are worse than those from OBP. For example, in the case of AR, the $\log$ AUC values from OBP are much better than those from ABP1, and only $7.0 \%$ of ToxCast actives have better docking scores from ABP1 than those from OBP (Table 4). However, ToxCast actives Nitrilotriacetic acid, lactofen, and 
Table 4 ToxCast active enrichment from allosteric pockets, and the consensus over different pockets

\begin{tabular}{|c|c|c|c|c|c|c|c|}
\hline Receptor & $\begin{array}{l}\log \mathrm{AUC}(\mathrm{EF} 1) \\
\text { from OBP }\end{array}$ & $\begin{array}{l}\log \mathrm{AUC}(\mathrm{EF} 1) \\
\text { from } \mathrm{ABP} 1\end{array}$ & $\begin{array}{l}\text { Consensus1 } \\
\log \text { AUC (EF1) }\end{array}$ & $\begin{array}{l}\text { ToxCast actives\% } \\
\text { favoring ABP1 }\end{array}$ & $\begin{array}{l}\log \mathrm{AUC}(\mathrm{EF} 1) \\
\text { from } \mathrm{ABP} 2\end{array}$ & $\begin{array}{l}\text { Consensus2 } \\
\log \mathrm{AUC}(\mathrm{EF} 1)\end{array}$ & $\begin{array}{l}\text { ToxCast } \\
\text { actives } \% \text { favor- } \\
\text { ing ABP } 2\end{array}$ \\
\hline $\mathrm{AR}^{*}$ & $35.3(9.4)$ & $22.4(1.0)$ & $31.4(\mathbf{1 0 . 8})$ & 7.0 & $16.2(1.0)$ & $31.3(\mathbf{1 0 . 8})$ & 6.1 \\
\hline GR & $29.3(7.6)$ & $27.0(5.3)$ & $32.6(7.6)$ & 19.0 & $15.4(2.4)$ & $32.4(7.6)$ & 5.4 \\
\hline PR & $31.1(15.8)$ & $27.1(10.5)$ & 33.1 (17.6) & 12.5 & $19.2(4.4)$ & $33.2(\mathbf{1 7 . 6})$ & 6.2 \\
\hline $\mathrm{ER} \alpha$ & 31.7 (12.6) & $23.3(4.2)$ & 27.1 (12.6) & 7.5 & $14.5(2.1)$ & $27.2(12.6)$ & 3.6 \\
\hline $\mathrm{ER} \beta$ & $28.2(8.1)$ & $23.3(2.8)$ & $31.0(\mathbf{9 . 0})$ & 12.5 & $14.6(2.8)$ & $30.9(\mathbf{9 . 0})$ & 3.6 \\
\hline $\operatorname{PPAR} \alpha$ & $21.2(7.9)$ & $28.5(5.3)$ & $32.6(7.9)$ & 35.0 & $13.8(2.7)$ & $32.4(7.9)$ & 4.0 \\
\hline $\operatorname{PPAR} \gamma$ & $21.0(4.6)$ & $21.0(2.8)$ & $22.6(3.7)$ & 21.6 & $15.6(2.8)$ & $23.2(3.7)$ & 3.4 \\
\hline $\mathrm{RAR} \alpha$ & $25.1(2.4)$ & 21.0 & $23.6(3.6)$ & 11.4 & $14.8(2.4)$ & $23.2(\mathbf{3 . 6})$ & 3.8 \\
\hline $\mathrm{ROR} \gamma^{\#}$ & $22.9(4.8)$ & $22.4(3.6)$ & $24.2(3.6)$ & 12.2 & $16.1(1.2)$ & $24.0(3.6)$ & 4.8 \\
\hline VDR & $21.3(1.8)$ & $19.4(2.4)$ & $21.7(1.8)$ & 4.2 & $16.9(1.1)$ & $21.8(1.8)$ & 3.4 \\
\hline $\mathrm{RXR} \alpha$ & $20.7(4.6)$ & $22.2(4.6)$ & 25.1 & 16.8 & $15.0(2.3)$ & $21.2(4.6)$ & 4.5 \\
\hline $\operatorname{LXR} \beta$ & $19.0(2.1)$ & $14.8(0.0)$ & $19.0(2.1)$ & 1.0 & $15.4(2.1)$ & $19.0(2.1)$ & 1.0 \\
\hline
\end{tabular}

$\log \mathrm{AUC}(\mathrm{EF} 1)$ from OBP, $\log \mathrm{AUC}(\mathrm{EF} 1)$ from the orthosteric binding pocket in the structure of the best resolution. Consensus1 logAUC/EF1, Consensus $\log \mathrm{AUC} / \mathrm{EF} 1$ from OBP and ABP1. Consensus2 logAUC/EF1, Consensus logAUC/EF1 from OBP, ABP1, and ABP2. ToxCast actives\% favoring ABP1, the percentage of ToxCAST actives that were scored better by ABP1 than OBP. Consensus1 logAUC/EF1 or Consensus2 $\log$ AUC/EF1 are highlighted in bold or italic fonts when they are $>10 \%$ better or worse than $\log$ AUC (EF1) from OBP

*For AR, the reported alternative binding pocket (ABP1) (PDB ID: 2PIW) was used for docking, the ABP1 in each of the other 11 NRs was derived by superposing the best resolution structure onto 2PIW

${ }^{\#}$ For ROR $\gamma$, the reported alternative binding pocket (ABP2) (PDB ID: 5C4T) was used for docking, the ABP2 in each of the other 11 NRs was derived by superposing the best resolution structure onto 5C4T

Consensus $1 \log \mathrm{AUC} / \mathrm{EF} 1$ or Consensus2 $\log \mathrm{AUC} / \mathrm{EF} 1$ are highlighted in bold or italic fonts when they are $>10 \%$ better or worse than $\log \mathrm{AUC}$ (EF1) from OBP

bensulide received better docking scores (data not shown) and ranks $(61,88,168)$ from ABP1 than those from OBP (231, 447, 884). Similarly, in the case of ROR $\gamma$, the $\log$ AUC values from OBP are much better than those from ABP2, and only $4.8 \%$ of ToxCast actives have better docking scores from ABP2 than those from OBP. However, ToxCast actives 5HPP-33 (thalidomide derivative), parafuchsin, and reservertol received better docking scores (data not shown) and ranks $(16,38,143)$ from ABP2 than those from OBP (1578, 1657, 808). In ABP2, the docked 5HPP-33 formed hydrogen bonding interactions with ALA497 and PHE498 using its hydroxy group (Fig. 3f). Similar receptor-ligand interactions can be seen in the ROR $\gamma$ crystal structure solved with bound ABP2 ligand (PDB ID: 5C4T).

\section{Prediction of novel fatty acids binding to PPARY}

PPAR $\gamma$ is one of the three PPAR isoforms $(\alpha, \beta$, and $\gamma)$. It is involved in transcriptional regulation of glucose and lipid metabolism (Yu et al. 1995; Lemberger et al. 1996; Desvergne and Wahli 1999; Tyagi et al. 2011), and mainly regulates adipose differentiation. Numerous natural endogenous and dietary lipids and their metabolites act as PPAR $\gamma$ activators, including polyunsaturated fatty acids (PUFAs) such as docosahexaenoic acid (DHA), and eicosapentanoic acid
(EPA). The PUFAs and saturated fatty acids play important roles in membrane structure, bioactive compound production, and cellular signaling processes. Nowadays, they are increasingly consumed as food additives and supplements, while the consumption of saturated fats and unsaturated fats is considered to be harmful and beneficial, respectively. Therefore, it is important to recognize dietary fatty acids that can activate PPAR $\gamma$ through binding. Such discovery is very useful for the hazard or risk assessments of food products and prioritize specific food components and/or additives for further experimental assessments.

In the benchmarking of ToxCast chemicals, the enrichment of PPAR $\gamma$ actives using four PPAR $\gamma$ structures and the hybrid scoring function $E^{\prime}{ }_{\text {DOCK }}$ is only 24.0 for $\log$ AUC and 4.8 for EF1 (Table 3). To facilitate PPAR $\gamma$ ligand identification out of fatty acids, we attempted to improve the existing docking-based potential EDC prediction method, following the same philosophy that consensus enrichment of more structures will be better than or comparable to that of fewer structures. Given the 222 crystal structures determined for PPAR $\gamma$, we added two more agonist-bound structures and two more antagonist-bound structures to the PPAR $\gamma$ structure dataset, in total 8 structures that were solved in complex with drug-like molecules but not fatty acids. When the ToxCast library was screened against these 8 structures 
with $E^{\prime}{ }_{\text {DOCK }}$ (only considering OBP), a better ToxCast active enrichment was achieved $(\log \mathrm{AUC}=28.9, \mathrm{EF} 1=7.4)$ (Table S5). The two EDCs BPA and DAP, that are known to bind and activate PPAR $\gamma$, are now ranked 9 and 11 (previously ranked 11 and 14) out of the 1768 ToxCast chemicals, respectively. These results pushed the upper limit of the prediction accuracy of our computational method, suggesting again the beneficial effect of the usage of multiple structures.

\section{Fatty acid docking analysis}

Thereafter, we applied this improved method to predict dietary fatty acids that bind to PPAR $\gamma$ and likely activate the receptor. A fatty acid database of 252 fatty acids was screened against the 8 structures of PPAR $\gamma$. In the topranked 25 fatty acids, we found that the fatty acids belong to 5 classes, including 8 furan fatty acids, 2 cyclopropyl fatty acids, 5 oxo fatty acids, 3 very long-chain fatty acids, and 7 PUFAs (Table S7). These fatty acids are well accommodated in the manner similar to known binders such as DHA and EPA. Based on $E_{\text {DOCK }}$ scores and chemical diversity, 7 unknown fatty acids belonging to different fatty acids classes were shortlisted for testing from top-ranked 25 fatty acids, including 2 furan fatty acids (furannonanoic acid (FNA), and furanundecanoic acid (FUA)), 1 cyclopropyl fatty acid (phytomonic acid (PTA)), 1 oxo fatty acid (ricinoleic acid (ROA)), 3 PUFAs (eicosatrienoic acid (ESA), pinolenic acid (PLA), and docosapentaenoic acid (DPA)). The very longchain fatty acids are commercially not available so we did not select them. These 7 unknown fatty acids and 2 known PPAR $\gamma$ binders/activators (eicosapentaenoic acid (EPA) and docosahexaenoic acid (DHA)) as control were selected for testing, in total 9 fatty acids.

To date, 28 crystal structures of PPAR $\gamma$ were solved in complex with fatty acids. Structure analysis showed that the carboxyl group in these fatty acids can form hydrogen bonds with SER289, HIS323, HIS449, and TYR473, which are reported to be vital for producing the maximum activity of compound through a direct stabilization of helix H12 and are responsible for the PPAR $\gamma$ transactivation activity (Itoh et al. 2008; Farce et al. 2009; Guasch et al. 2011). In addition, these fatty acids also form close contacts with PHE282, CYS285, GLN286, ARG288, VAL290, GLU295, LYS319, TYR327, MET334, VAL339, SER342, TYR355, PHE 363, MET364, LYS367, and LEU453 (hot-spots). The docking poses of the 9 shortlisted fatty acids show similar binding patterns as those observed in the 28 crystal structures. For example, the terminal carboxyl group of FNA forms hydrogen bonding interactions with SER289, HIS323, TYR327 and TYR473, and its unsaturated chain forms hydrophobic interactions with PHE282, CYS285, GLN286, MET364 and LEU453 (Fig. 5a and b). The docking scores of FNA, FUA, and PTA are better than those of DPA, ESA, PLA, and
ROA probably because the furan rings in FNA and FUA, and the cyclopropane ring in PTA form more favorable hydrophobic interactions with CYS285, MET364, and VAL339 in comparison to the linear chains in other four fatty acids (Table 5).

\section{PPARy binding verification}

We tested the binding of fatty acids to PPAR $\gamma$ through SPR analysis. As predicted, all the tested fatty acid exhibited weak binding to PPAR $\gamma$ with the calculated affinities (Kd) ranging from micromole to millimole. Specifically, EPA and DHA, which have been reported to activate PPAR $\gamma$ (Xu et al. 1999), showed a similar binding affinity with Kds of $\sim 600 \mu \mathrm{M}$. The FNA (Fig. 5c and d), FUA, and PTA exhibited stronger binding than DHA and EPA (Fig. S1), while DPA, ESA, PLA and ROA showed weaker binding than DHA, which was well supported by their docking scores (Table 5). The higher binding affinity from PTA, FNA, and FUA are likely due to presence of a hydrophobic carbon ring (furan in FNA and FUA, cyclopropane in PTA) that forms more favorable hydrophobic interactions with CYS285, MET364, VAL339, and LEU453 compared to other four linear chain fatty acids, and the lower affinities of DPA, ESA, PLA and ROA are probably due to reduced carbon chain or degree of saturation.. Long-chain fatty acids (LCFA), such as DHA and EPA, have been identified as endogenous ligands of PPAR $\gamma$ and can regulate the lipid metabolism through modulating the transcriptional activity of PPAR $\gamma$ (Xu et al. 1999; Itoh et al. 2008). However, the LCFA can be pushed out of the orthosteric pocket by synthetic ligands, as their affinities are much lower than synthetic ligands (Itoh et al. 2008). This notion agrees well with our result that the LCFAs displayed weak binding to PPAR $\gamma$ in molecular docking and SPR assays. Mutations in these fatty acid-binding residues have been found to be associated with various metabolic and inflammatory diseases, such as obesity (Ristow et al. 1998; Beamer et al. 1998), Insulin resistance, diabetes (Barroso et al. 1999; Majithia et al. 2014), hypertension (Barroso et al. 1999), lipodystrophy (Francis et al. 2006; Miehle et al. 2016), dyslipidaemia (Capaccio et al. 2010), colon and bladder cancer (Sarraf et al. 1999; Liu et al. 2019). For example, the V290M mutation is associated with severe insulin resistance, diabetes mellitus, and hypertension (Fig. 5e, f) (Barroso et al. 1999). This mutant inhibits PPAR $\gamma$ function in a dominant-negative manner, markedly attenuating the transcriptional function of PPAR $\gamma$. Other PPAR $\gamma$-deficient hot-spot residue mutations in the fatty acid-binding site are associated with colon cancer such as Q286P, K319X, R288H/A, S289C (Sarraf et al. 1999) and with lipodystrophy (Francis et al. 2006; Miehle et al. 2016) such as Y355X, Y473A, R165T and L339X. For two of these mutants Y355A and V290M, we 
A
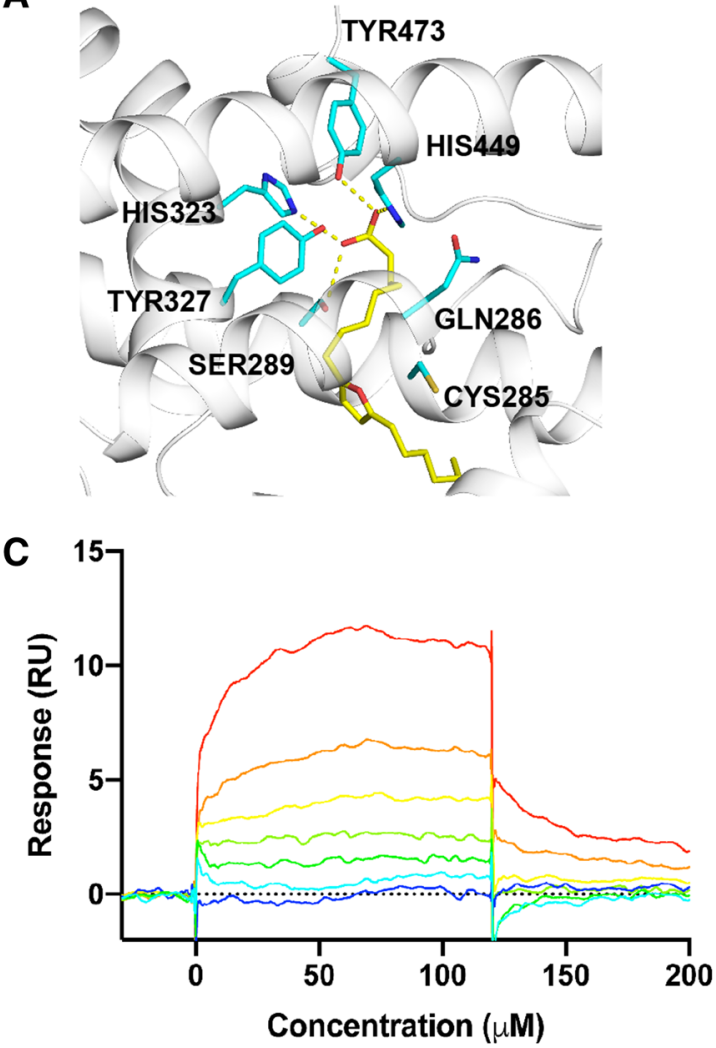

E

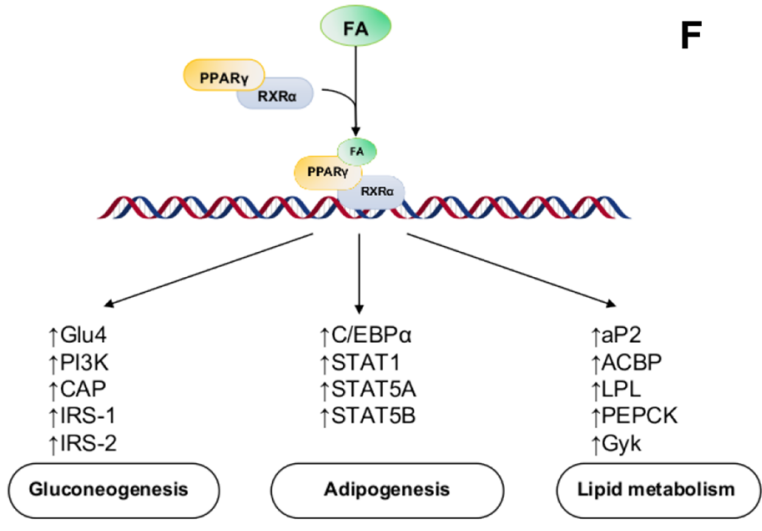

B
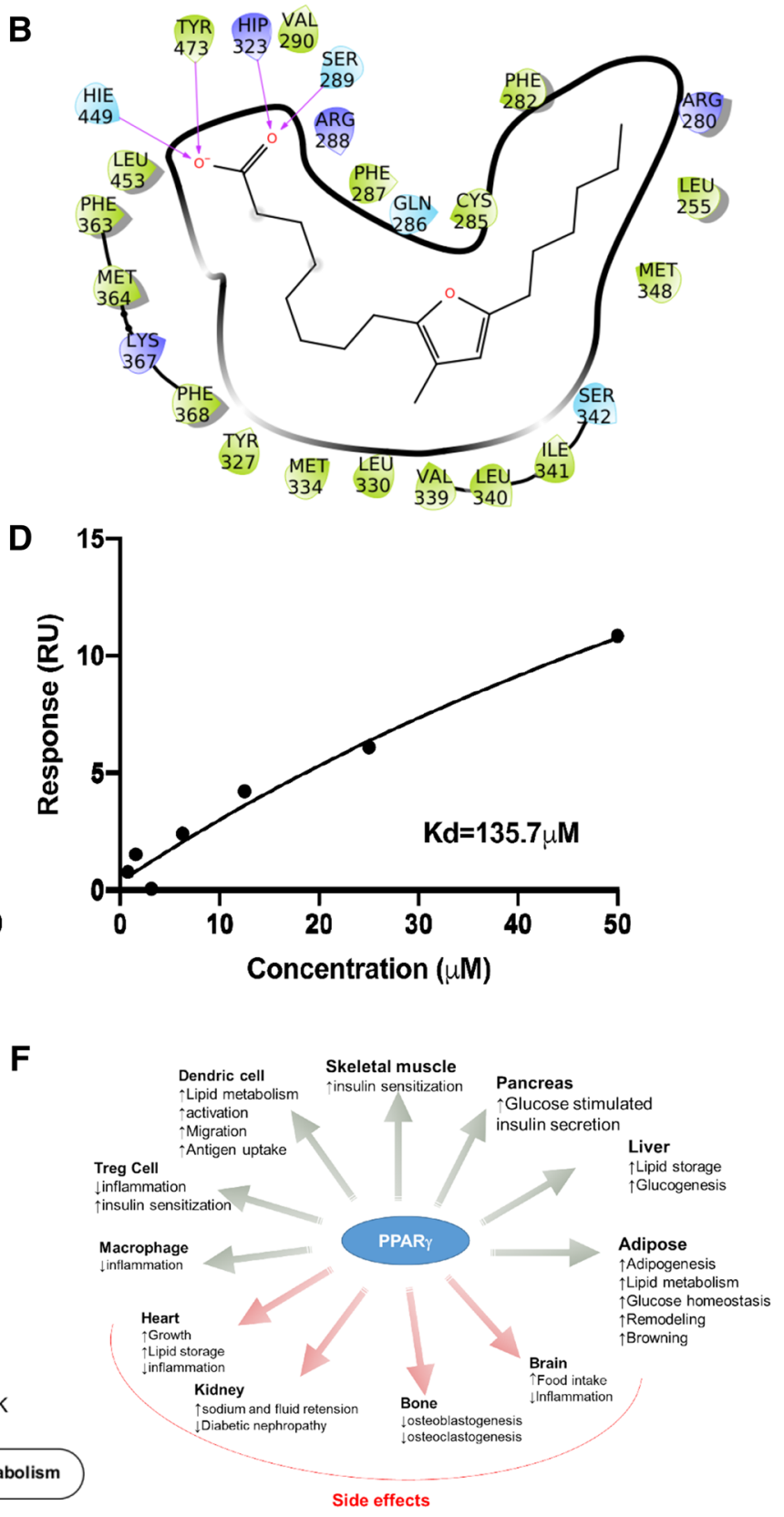

rium binding curve of FNA to PPAR $\gamma$ LBD, e Functional patterns of PPAR $\gamma$, involved in adipocyte differentiation, lipid metabolism and glucose homeostasis, $\mathbf{f}$ Pathophysiology effects of PPAR $\gamma$

structures, respectively (Table S8). These results suggest that we may expect weaker binding of these fatty acids to the PPAR $\gamma$ mutants Y355A and V290M, and subsequently reduced transcriptional activity with respect to that of the wild type PPAR $\gamma$. The long-term malfunction of PPAR $\gamma$ may lead to an increased risk of metabolic disorders such as insulin resistance, diabetes mellitus, or partial lipodystrophy (Barroso et al. 1999; Francis et al. 2006). 
Table 5 Docking and binding assay data for 9 tested fatty acids

\begin{tabular}{lllllc}
\hline No. & Fatty acids & Hybrid score & $\mathrm{Kd}(\mu \mathrm{M})$ & $\mathrm{Rmax}(\mathrm{RU})$ & $\mathrm{Chi}^{2}$ \\
\hline 1. & Furannonanoic acid (FNA) & -11.19 & 135.7 & 38.55 & 0.62 \\
2. & Furanundcanoic acid (FUA)* & -11.16 & 248.7 & 459.3 & 12.5 \\
3. & Docosahexaenoic acid (DHA) & -11.14 & 593 & 281 & 1.14 \\
4. & Eicosapentaenoic acid (EPA) & -10.12 & 629.4 & 136 & 1.27 \\
5. & Doceapentaenoic acid (DPA) & -10.10 & 3960 & 2167 & 0.08 \\
6. & Eicosatrienoic acid (ESA) & -10.01 & $>10,000.00$ & $>10,000.00$ & 3.19 \\
7. & Phytomonic acid (PTA) & -9.89 & 102.9 & 33.28 & 0.1 \\
8. & Ricinoleic acid (ROA) & -9.70 & $>10,000.00$ & $>10,000.00$ & 0.16 \\
9. & Pinolenic acid (PLA) & -9.27 & $>10,000.00$ & $>10,000.00$ & 0.74 \\
\hline
\end{tabular}

*Chip coupled with 12000RU ligand (PPAR $\gamma$ LBD) was used for FUA binding analysis. $R U$ response units. $\mathrm{Chi}^{2}$ is a measure of the average deviation of the experimental data from the fitted curve. Lower Chi ${ }^{2}$ values indicate a better fit; Rmax, the amount of ligand (in RUs) immobilized

\section{Confirmed fatty acids in diets}

Among the fatty acids that exhibited higher affinity to PPAR $\gamma$ than endogenous ligands such as DHA and EPA, FNA (9M5) was reported to enhance adipogensis (Lauvai et al. 2019), and to promote significantly more lipid accumulation than PUFAs like DHA and EPA even at lower concentrations, consistent with our results. However, it is currently unknown if FNA can directly interact with and activate PPAR $\gamma$. Our study provides a plausible mechanism that can explain the observed phenotypic effects of FNA. Due to its strong binding affinity experimentally verified in our study, FNA could outcompete natural activators such as oelic, linoleic, lauric and arachidonic acid upon binding to PPAR $\gamma$. The same behaviour could be observed in related analogues of FNA and FUA (Table S6) such as 9D5, 11D5 and 7D5. These furan fatty acids are primarily found in a wide range of diets such as fish liver oil (at the level of 1-6\%) and freshwater fish liver oil (up to 25\%), plant oils, fruits (e.g. lemon, olives, strawberry), vegetables (e.g. cabbage and potato), and mushrooms (Spiteller 2005; Xu et al. 2017). Similarly, PTA as a stronger binder of PPAR $\gamma$, than DHA and EPA, is also found in various dietary products such as milk (Caligiani et al. 2014), rapseed oil (Berdeaux et al. 2010), mushrooms, and probiotics (e.g. lactobacillus lipids) (Karine Pedneault et al. 2006; Nandakumar and Tan 2008). Although PTA is saturated fatty acid, it can be highly reactive because of its highly strained cyclopropane ring at 11, 12-position. In particular, strained cyclopropane rings can react with thiol/sulfur groups (i.e. with active cysteine residues in receptors). In PPAR $\gamma$ active site, we noticed a reactive cysteine (CYS285), which can form covalent bond with the strained cyclopropane ring of PTA, like 15d-PGJ2 (endogenous ligand), which activates PPAR $\gamma$ through covalent bond formation with CYS285 (Liberato et al. 2012). This could partially account for the relatively high affinity of PTA against PPAR $\gamma$. Other fatty acids chemically similar to PTA could resemble its strong interaction against PPAR $\gamma$, such as dihydro sterculic acid and cyclopropenoic acid derivatives (e.g. sterculic acid and malvalic acid). Dihydrosterculic acid and sterculic acid are available in sterculia foetida $(\sim 50 \%)$ and cotton-seed oil $(2 \%)$. The sterculia foetida oil diet for rats showed healthy effects such as reduced reproductive function, retarted growth, and weight gain (Nixon et al. 1974; Eisele et al. 1977; Matlock et al. 1985; Peláez et al. 2020). Similar impact can be anticipated for PTA as it is chemically similar to sterculic acid and shows high binding affinity against PPAR $\gamma$. Among the fatty acids we selected, DPA is also confirmed to bind to PPAR $\gamma$, weaker than DHA and EPA. DPA is a $\omega-3$ fatty acid that belongs to PUFA family; it is a metabolic product of the parent fatty acid is $\alpha$-linolenic acid.

\section{Conclusions}

\section{Overview}

In this study, we constructed an in silico method for potential EDC prediction, based on molecular docking. This method, when evaluated on 12 nuclear receptors (NRs), showed the reasonable capability to recognize ToxCast actives out of inactives (logAUC values range from 21.8 to 39.4, EF1 values range from 1.8 to 24.3 , see Table 3 ), nearly 2 to 10 times better than random selection. These results suggest aspects to better exploit structure-based approaches in potential EDC prediction: consensus over docking screens against multiple protein structures, chemical similarity-weighted docking scores, alternative binding sites (ABPs).

\section{Consensus over multiple receptor structures}

Consensus enrichment scores over multiple receptor structures covering both agonist-bound and antagonist-bound 
states, computed by selecting the best docking score for each chemical, can perform consistently better than or comparable to best-performing single structure (Table 2). When the performance of each crystal structure in EDC recognition is not known, the consensus selection over multiple receptor structures is the most suitable method for potential EDC prediction.

\section{Hybrid scoring including ligand information}

The hybrid (chemical similarity-weighted) scoring approach can perform better than both the protein-based (docking) approach and the ligand-based (chemical similarity) approach (Table 3; Fig. 4), when applied to results from every single structure, and to that from consensus over multiple structures. The proposed method, combining consensus over multiple structures and hybrid scoring scheme, could be an optimal approach for potential EDC prediction, when both protein structure and ligand information are available for the target.

\section{Alternative binding site}

ToxCast actives can be better scored (from 1 to $35 \%$ ) by ABPs than the orthosteric binding site (OBP) (Table 4), therefore, we recommend to take ABPs into account in potential EDC prediction especially when ABPs have been verified by experiments. However, it may not be straightforward to use the consensus over OBP and $\mathrm{ABP}(\mathrm{s})$ in the high-throughput in silico prediction, as reduced accuracy are observed in some cases.

\section{Fatty acids identified as PPAR ligands}

The in silico method was applied to the identification of novel fatty acids binding to $\operatorname{PPAR} \gamma$, which is a key protein in transcriptional regulation of glucose and lipid metabolism, and involved in various metabolic and inflammatory diseases. A total of 7 fatty acids were predicted as ligand (likely activator) candidates, 4 out of which were verified by subsequent binding tests, including 3 fatty acids (FNA, FUA and PTA $)$ of better binding affinity $(\mathrm{Kd}=100-250 \mu \mathrm{M})$ than DHA and EPA. Mutations of binding site residues of these fatty acids have been found in cancer, diabetes, and hypertension.

\section{Future perspectives}

In silico prediction of chemical toxicity and understanding the molecular initiating events remain major challenges in toxicology. In this study, we showed on $12 \mathrm{NRs}$ that a virtual screening method based on molecular docking can contribute to addressing these challenges. The utility of this method can be enlarged by including all 45 NRs that have at least one crystal structure solved (out of 48 identified NRs) (Lagarde et al. 2014; Weikum et al. 2018). In addition, only the ligand-binding domains (LBDs) of NRs were targeted in this study. However, it has been suggested that the DNA binding domains (DBDs) of NRs and even the DNA sites recognized by NRs can also be targeted by ligands (Brodie 2005; Meijsing et al. 2009; Li et al. 2014; Dalal et al. 2014; Shizu et al. 2018; Frank et al. 2018; Pal et al. 2019; Veras Ribeiro Filho et al. 2019). Thus we expect that the application of our in silico method to these new molecular interfaces will also facilitate potential EDC prediction. Subsequent in vitro assessments may be performed to better understand the toxicodynamics of these suspected EDCs, establish their concentration-dependent effects to cellular functions, and assess if they may pose acceptable or unacceptable risks to the relevant exposed human populations.

Acknowledgements This work is supported by Biomedical Research Council of Agency for Science, Technology and Research (A*STAR) and the ToxMAD project under the Innovations in Food and Chemical Safety Programme (Grant No. H18/01/a0/B14)

Author contributions CKJ performed virtual screening and interpreted the data under the supervision of HF. YH performed Surface Plasmon Resonance (SPR) Analysis and interpreted the data under supervision of HWS. LNZ helped in protein database construction. LHL and SMS helped design the project. CKJ, YH, LHL, SMS, and HWS contributed to the writing of manuscript. HF designed and supervised the whole project, analyzed the data, and wrote the manuscript. All authors read and approved the final manuscript.

Open Access This article is licensed under a Creative Commons Attribution 4.0 International License, which permits use, sharing, adaptation, distribution and reproduction in any medium or format, as long as you give appropriate credit to the original author(s) and the source, provide a link to the Creative Commons licence, and indicate if changes were made. The images or other third party material in this article are included in the article's Creative Commons licence, unless indicated otherwise in a credit line to the material. If material is not included in the article's Creative Commons licence and your intended use is not permitted by statutory regulation or exceeds the permitted use, you will need to obtain permission directly from the copyright holder. To view a copy of this licence, visit http://creativecommons.org/licenses/by/4.0/.

\section{References}

Bain DL, Heneghan AF, Connaghan-Jones KD, Miura MT (2007) Nuclear receptor structure: implications for function. Annu Rev Physiol 69:201-220. https://doi.org/10.1146/annurev.physi ol.69.031905.160308

Barroso I, Gurnell M, Crowley VEF et al (1999) Dominant negative mutations in human PPAR $\gamma$ associated with severe insulin resistance, diabetes mellitus and hypertension. Nature 402:880-883. https://doi.org/10.1038/47254

Beamer BA, Yen CJ, Andersen RE et al (1998) Association of the Pro12Ala variant in the peroxisome proliferator-activated receptorgamma2 gene with obesity in two Caucasian populations. Diabetes 47:1806-1808. https://doi.org/10.2337/diabetes.47.11.1806 
Berdeaux O, Gregoire S, Fournier C et al (2010) Detection of lactobacillic acid in low erucic rapeseed oil-A note of caution when quantifying cyclic fatty acid monomers in vegetable oils. Chem Phys Lipids 163:698-702. https://doi.org/10.1016/j.chemphysli p.2010.07.002

Bordoni A, Di Nunzio M, Danesi F, Biagi PL (2006) Polyunsaturated fatty acids: from diet to binding to ppars and other nuclear receptors. Genes Nutr 1:95-106. https://doi.org/10.1007/BF02829951

Brodie J (2005) Intra-domain communication between the N-terminal and DNA-binding domains of the androgen receptor: modulation of androgen response element DNA binding. J Mol Endocrinol 34:603-615. https://doi.org/10.1677/jme.1.01723

Caligiani A, Marseglia A, Palla G (2014) An overview on the presence of cyclopropane fatty acids in milk and dairy products. J Agric Food Chem 62:7828-7832. https://doi.org/10.1021/jf4057204

Canvas, Schrödinger, LLC, New York, NY 2018

Capaccio D, Ciccodicola A, Sabatino L et al (2010) A novel germline mutation in peroxisome proliferator-activated receptor $\gamma$ gene associated with large intestine polyp formation and dyslipidemia. Biochim Biophys Acta Mol Basis Dis 1802:572-581. https://doi. org/10.1016/j.bbadis.2010.01.012

Capuzzi SJ, Politi R, Isayev O et al (2016) QSAR modeling of Tox21 challenge stress response and nuclear receptor signaling toxicity assays. Front Environ Sci. https://doi.org/10.3389/fenvs .2016 .00003

Carlson H (2002) Protein flexibility is an important component of structure-based drug discovery. Curr Pharm Des 8:1571-1578. https://doi.org/10.2174/1381612023394232

Cavasotto C, Singh N (2008) Docking and high throughput docking: successes and the challenge of protein flexibility. Curr Comput Aided-Drug Des 4:221-234. https://doi.org/10.2174/1573409087 85747474

Cleves AE, Jain AN (2020) Structure- and ligand-based virtual screening on DUD-E + : performance dependence on approximations to the binding pocket. J Chem Inf Model. https://doi.org/10.1021/ acs.jcim.0c00115

Cohen Hubal EA, Richard A, Aylward L et al (2010) Advancing exposure characterization for chemical evaluation and risk assessment. J Toxicol Environ Heal Part B 13:299-313. https://doi. org/10.1080/10937404.2010.483947

Cozzini P, Kellogg GE, Spyrakis F et al (2008) Target flexibility: an emerging consideration in drug discovery and design $\uparrow$. J Med Chem 51:6237-6255. https://doi.org/10.1021/jm800562d

Dalal K, Roshan-Moniri M, Sharma A et al (2014) Selectively targeting the DNA-binding domain of the androgen receptor as a prospective therapy for prostate cancer. J Biol Chem 289:26417-26429. https://doi.org/10.1074/jbc.M114.553818

Desvergne B, Wahli W (1999) Peroxisome proliferator-activated receptors: nuclear control of metabolism. Endocr Rev 20:649-688. https://doi.org/10.1210/er.20.5.649

Diamanti-Kandarakis E, Bourguignon J-P, Giudice LC et al (2009) Endocrine-disrupting chemicals: an endocrine society scientific statement. Endocr Rev 30:293-342. https://doi.org/10.1210/ er.2009-0002

Dix DJ, Houck KA, Martin MT et al (2007) The ToxCast program for prioritizing toxicity testing of environmental chemicals. Toxicol Sci 95:5-12. https://doi.org/10.1093/toxsci/kfl103

Eisele TA, Yoss JK, Nixon JE et al (1977) Rat urinary metabolites of [9,10-methylene-14C]sterculic acid. Biochim Biophys Acta Lipids Lipid Metab 488:76-87. https://doi.org/10.1016/00052760(77)90124-2

European Council (2006) European Commision. REGULATION (EC) No 1907/2006 OF THE EUROPEAN PARLIAMENT AND OF THE COUNCIL of 18 December 2006 concerning the Registration, Evaluation, Authorisation and Restriction of Chemicals (REACH), establishing a European Chemicals Agency, amend

Ewing T, Baber JC, Feher M (2006) Novel 2D fingerprints for ligandbased virtual screening. J Chem Inf Model 46:2423-2431. https ://doi.org/10.1021/ci060155b

Fan H, Irwin JJ, Sali A (2012) Computational drug discovery and design. Springer, New York

Fan H, Irwin JJ, Webb BM et al (2009) Molecular docking screens using comparative models of proteins. J Chem Inf Model 49:2512-2527. https://doi.org/10.1021/ci9003706

Farce A, Renault N, Chavatte P (2009) Structural insight into PPAR $\gamma$ ligands binding. Curr Med Chem 16:1768-1789. https://doi. org/10.2174/092986709788186165

Foster JM, Moreno P, Fabregat A et al (2013) LipidHome: a database of theoretical lipids optimized for high throughput mass spectrometry lipidomics. PLoS ONE 8:e61951. https://doi.org/10.1371/ journal.pone.0061951

Fradera X, de la Cruz X, Silva CHTP et al (2002) Ligand-induced changes in the binding sites of proteins. Bioinformatics 18:939948. https://doi.org/10.1093/bioinformatics/18.7.939

Francis GA, Li G, Casey R et al (2006) Peroxisomal proliferator activated receptor- $\gamma$ deficiency in a Canadian kindred with familial partial lipodystrophy type 3 (FPLD3). BMC Med Genet 7:3. https://doi.org/10.1186/1471-2350-7-3

Frank F, Okafor CD, Ortlund EA (2018) The first crystal structure of a DNA-free nuclear receptor DNA binding domain sheds light on DNA-driven allostery in the glucocorticoid receptor. Sci Rep 8:13497. https://doi.org/10.1038/s41598-018-31812-9

Glide, Schrödinger, LLC, New York, NY 2018

Guasch L, Sala E, Valls C et al (2011) Structural insights for the design of new PPARgamma partial agonists with high binding affinity and low transactivation activity. J Comput Aided Mol Des 25:717-728. https://doi.org/10.1007/s10822-011-9446-9

https://lipidbank.jp/

https://www.ebi.ac.uk/chembl/

https://www.epa.gov/chemical-research/toxicity-forecaster-toxcasttmdata ToxCast

https://www.rcsb.org/

Huang P, Chandra V, Rastinejad F (2010) Structural overview of the nuclear receptor superfamily: insights into physiology and therapeutics. Annu Rev Physiol 72:247-272. https://doi.org/10.1146/ annurev-physiol-021909-135917

Huang SY, Li M, Wang J, Pan Y (2016) HybridDock: a hybrid proteinligand docking protocol integrating protein- and ligand-based approaches. J Chem Inf Model 56:1078-1087. https://doi. org/10.1021/acs.jcim.5b00275

Hussain F, Basu S, Heng JJH et al (2020) Predicting direct hepatocyte toxicity in humans by combining high-throughput imaging of HepaRG cells and machine learning-based phenotypic profiling. Arch Toxicol. https://doi.org/10.1007/s00204-020-02778-3

Itoh T, Fairall L, Amin K et al (2008) Structural basis for the activation of PPAR $\gamma$ by oxidized fatty acids. Nat Struct Mol Biol 15:924-931. https://doi.org/10.1038/nsmb.1474

Judson R, Richard A, Dix D et al (2008) ACToR-Aggregated computational toxicology resource. Toxicol Appl Pharmacol 233:7-13. https://doi.org/10.1016/j.taap.2007.12.037

Judson R, Richard A, Dix DJ et al (2009) The toxicity data landscape for environmental chemicals. Environ Health Perspect 117:685695. https://doi.org/10.1289/ehp.0800168

Karine PEDNEAULT, Paul ANGERS, André GOSSELIN, Russell JTWEDDELL (2006) Fatty acid composition of lipids from mushrooms belonging to the family Boletaceae. Mycol Res 110:1179-1183. https://doi.org/10.1016/j.mycres.2006.05.006 
Kavlock R, Chandler K, Houck K et al (2012) Update on EPA's ToxCast program: providing high throughput decision support tools for chemical risk management. Chem Res Toxicol 25:12871302. https://doi.org/10.1021/tx3000939

Kersten S, Desvergne B, Wahli W (2000) Roles of PPARs in health and disease. Nature 405:421-424. https://doi.org/10.1038/35013000

Kitchen DB, Decornez H, Furr JR, Bajorath J (2004) Docking and scoring in virtual screening for drug discovery: methods and applications. Nat Rev Drug Discov 3:935-949. https://doi.org/10.1038/ $\operatorname{nrd} 1549$

Kleinstreuer NC, Ceger P, Watt ED et al (2017) Development and validation of a computational model for androgen receptor activity. Chem Res Toxicol 30:946-964. https://doi.org/10.1021/acs. chemrestox.6b00347

Kliewer SA, Sundseth SS, Jones SA et al (1997) Fatty acids and eicosanoids regulate gene expression through direct interactions with peroxisome proliferator-activated receptors and. Proc Natl Acad Sci 94:4318-4323. https://doi.org/10.1073/pnas.94.9.4318

Knegtel RM, Kuntz ID, Oshiro CM (1997) Molecular docking to ensembles of protein structures. J Mol Biol 266:424-440. https ://doi.org/10.1006/jmbi.1996.0776

Knudsen TB, Houck KA, Sipes NS et al (2011) Activity profiles of 309 ToxCast $^{\mathrm{TM}}$ chemicals evaluated across 292 biochemical targets. Toxicology 282:1-15. https://doi.org/10.1016/j.tox.2010.12.010

Kortagere S, Krasowski MD, Reschly EJ et al (2010) Evaluation of computational docking to identify pregnane $\mathrm{X}$ receptor agonists in the ToxCast database. Environ Health Perspect 118:14121417. https://doi.org/10.1289/ehp. 1001930

Lack NA, Axerio-Cilies P, Tavassoli P et al (2011) Targeting the binding function 3 (BF3) site of the human androgen receptor through virtual screening. J Med Chem 54:8563-8573. https:// doi.org/10.1021/jm201098n

Lagarde N, Ben Nasr N, Jérémie A et al (2014) NRLiSt BDB, the manually curated nuclear receptors ligands and structures benchmarking database. J Med Chem 57:3117-3125. https://doi. org/10.1021/jm500132p

Lallous N, Leblanc E, Munuganti RSN et al (2016) Targeting binding function- 3 of the androgen receptor blocks its co-chaperone interactions, nuclear translocation, and activation. Mol Cancer Ther 15:2936-2945. https://doi.org/10.1158/1535-7163.MCT-16-0354

Lauvai J, Becker A, Lehnert K et al (2019) The Furan fatty acid 9M5 acts as a partial ligand to peroxisome proliferator-activated receptor gamma and enhances adipogenesis in 3T3-L1 preadipocytes. Lipids 54:277-288. https://doi.org/10.1002/lipd.12152

Lee J-YJ, Miller JA, Basu S et al (2018) Building predictive in vitro pulmonary toxicity assays using high-throughput imaging and artificial intelligence. Arch Toxicol 92:2055-2075. https://doi. org/10.1007/s00204-018-2213-0

Lemberger T, Desvergne B, Wahli W (1996) Peroxisome proliferatoractivated receptors: a nuclear receptor signaling pathway in lipid physiology. Annu Rev Cell Dev Biol 12:335-363. https://doi. org/10.1146/annurev.cellbio.12.1.335

Li H, Ban F, Dalal K et al (2014) Discovery of small-molecule inhibitors selectively targeting the DNA-binding domain of the human androgen receptor. J Med Chem 57:6458-6467. https://doi. org/10.1021/jm500802j

Liberato MV, Nascimento AS, Ayers SD et al (2012) Medium chain fatty acids are selective peroxisome proliferator activated receptor (PPAR) $\gamma$ activators and pan-PPAR partial agonists. PLoS ONE 7:e36297. https://doi.org/10.1371/journal.pone.0036297

LigPrep, Schrödinger, LLC, New York, NY 2018

Lim VJY, Du W, Chen YZ, Fan H (2018) A benchmarking study on virtual ligand screening against homology models of human GPCRs. Proteins Struct Funct Bioinforma 86:978-989. https:// doi.org/10.1002/prot.25533
Liu C, Tate T, Batourina E et al (2019) Pparg promotes differentiation and regulates mitochondrial gene expression in bladder epithelial cells. Nat Commun 10:4589. https://doi.org/10.1038/s4146 7-019-12332-0

Lynch C, Sakamuru S, Huang R et al (2017) Identifying environmental chemicals as agonists of the androgen receptor by using a quantitative high-throughput screening platform. Toxicology 385:48-58. https://doi.org/10.1016/j.tox.2017.05.001

Ma B, Shatsky M, Wolfson HJ, Nussinov R (2009) Multiple diverse ligands binding at a single protein site: a matter of pre-existing populations. Protein Sci 11:184-197. https://doi.org/10.1110/ ps. 21302

Madrazo JA, Kelly DP (2008) The PPAR trio: regulators of myocardial energy metabolism in health and disease. J Mol Cell Cardiol 44:968-975. https://doi.org/10.1016/j.yjmcc.2008.03.021

Majithia AR, Flannick J, Shahinian P et al (2014) Rare variants in PPARG with decreased activity in adipocyte differentiation are associated with increased risk of type 2 diabetes. Proc Natl Acad Sci 111:13127-13132. https://doi.org/10.1073/pnas.1410428111

Manco M, Calvani M, Mingrone G (2004) Effects of dietary fatty acids on insulin sensitivity and secretion. Diabetes Obes Metab 6:402-413. https://doi.org/10.1111/j.1462-8902.2004.00356.x

Marion-Letellier R, Savoye G, Ghosh S (2016) Fatty acids, eicosanoids and PPAR gamma. Eur J Pharmacol 785:44-49. https:// doi.org/10.1016/j.ejphar.2015.11.004

Matlock JP, Nixon JE, Pawlowski NE (1985) Altered lipid metabolism and impaired clearance of plasma cholesterol in mice fed cyclopropenoid fatty acids. Toxicol Appl Pharmacol 80:457-466. https ://doi.org/10.1016/0041-008X(85)90390-4

Matthäus B (2012) The new database Seed Oil Fatty Acids (SOFA). Lipid Technol 24:230-234. https://doi.org/10.1002/lite.20120 0227

McCammon JA (2005) Target flexibility in molecular recognition. Biochim Biophys Acta Proteins Proteom 1754:221-224. https://doi. org/10.1016/j.bbapap.2005.07.041

Meijsing SH, Pufall MA, So AY et al (2009) DNA binding site sequence directs glucocorticoid receptor structure and activity. Science (80-) 324:407-410. https://doi.org/10.1126/scien ce. 1164265

Miehle K, Porrmann J, Mitter D et al (2016) Novel peroxisome proliferator-activated receptor gamma mutation in a family with familial partial lipodystrophy type 3. Clin Endocrinol (Oxf) 84:141-148. https://doi.org/10.1111/cen.12837

Mysinger MM, Carchia M, Irwin JJ, Shoichet BK (2012) Directory of useful decoys, enhanced (DUD-E): better ligands and decoys for better benchmarking. J Med Chem 55:6582-6594. https://doi. org/10.1021/jm300687e

Mysinger MM, Shoichet BK (2010) Rapid context-dependent ligand desolvation in molecular docking. J Chem Inf Model 50:15611573. https://doi.org/10.1021/ci100214a

Nandakumar M, Tan M-W (2008) Gamma-linolenic and stearidonic acids are required for basal immunity in Caenorhabditis elegans through their effects on p38 MAP kinase activity. PLoS Genet 4:e1000273. https://doi.org/10.1371/journal.pgen.1000273

Nicolotti O, Benfenati E, Carotti A et al (2014) REACH and in silico methods: an attractive opportunity for medicinal chemists. Drug Discov Today 19:1757-1768. https://doi.org/10.1016/j.drudi s.2014.06.027

Nicolotti O, Giangreco I, Miscioscia TF, Carotti A (2009) Improving quantitative structure-activity relationships through multiobjective optimization. J Chem Inf Model 49:2290-2302. https://doi. org/10.1021/ci9002409

Nicolotti O, Miscioscia TF, Carotti A et al (2008) An integrated approach to ligand- and structure-based drug design: development and application to a series of serine protease inhibitors. J Chem Inf Model 48:1211-1226. https://doi.org/10.1021/ci800015s 
Nixon JE, Eisele TA, Wales JH, Sinnhuber RO (1974) Effect of subacute toxic levels of dietary cyclopropenoid fatty acids upon membrane function and fatty acid composition in the rat. Lipids 9:314-321. https://doi.org/10.1007/BF02533107

Pal SK, Tew BY, Lim M et al (2019) Mechanistic Investigation of the androgen receptor DNA-binding domain inhibitor pyrvinium. ACS Omega 4:2472-2481. https://doi.org/10.1021/acsomega.8b03205

Paul Friedman K, Gagne M, Loo L-H et al (2020) Utility of in vitro bioactivity as a lower bound estimate of in vivo adverse effect levels and in risk-based prioritization. Toxicol Sci 173:202-225. https:// doi.org/10.1093/toxsci/kfz201

Peláez R, Pariente A, Pérez-Sala Á, Larráyoz IM (2020) Sterculic acid: the mechanisms of action beyond stearoyl-CoA desaturase inhibition and therapeutic opportunities in human diseases. Cells 9:140. https://doi.org/10.3390/cells9010140

Protein Preparation Wizard, Schrödinger, LLC, NewYork, NY 2018; Epik, Schrödinger, LLC, New York, NY, 2018; Impact, Schrödinger, LLC, New York, NY, 2018; Prime, Schrödinger, LLC, New York, NY, 2018

Reif DM, Martin MT, Tan SW et al (2010) Endocrine profling and prioritization of environmental chemicals using toxcast data. Environ Health Perspect 118:1714-1720. https://doi.org/10.1289/ehp.1002180

Ribeiro MDRCJ, Kushner PhDPJ, Baxter MDJD (1995) The nuclear hormone receptor gene superfamily. Annu Rev Med 46:443-453. https ://doi.org/10.1146/annurev.med.46.1.443

Ristow M, Müller-Wieland D, Pfeiffer A et al (1998) Obesity associated with a mutation in a genetic regulator of adipocyte differentiation. N Engl J Med 339:953-959. https://doi.org/10.1056/NEJM199810 013391403

Robinson-Rechavi M, Garcia HE, Laudet V (2003) The nuclear receptor superfamily. J Cell Sci 116:585-586. https://doi.org/10.1242/ jcs.00247

Rotroff DM, Dix DJ, Houck KA et al (2013) Using in vitro high throughput screening assays to identify potential endocrine-disrupting chemicals. Environ Health Perspect 121:7-14. https://doi. org/10.1289/ehp.1205065

Sampath H, Ntambi JM (2004) Polyunsaturated fatty acid regulation of gene expression. Nutr Rev 62:333-339. https://doi. org/10.1111/j.1753-4887.2004.tb00058.x

Sanderson JT (2006) The steroid hormone biosynthesis pathway as a target for endocrine-disrupting chemicals. Toxicol Sci 94:3-21. https ://doi.org/10.1093/toxsci/kfl051

Sarraf P, Mueller E, Smith WM et al (1999) Loss-of-function mutations in PPAR $\gamma$ associated with human colon cancer. Mol Cell 3:799804. https://doi.org/10.1016/S1097-2765(01)80012-5

Sastry M, Lowrie JF, Dixon SL, Sherman W (2010) Large-scale systematic analysis of 2D fingerprint methods and parameters to improve virtual screening enrichments. J Chem Inf Model 50:771-784. https ://doi.org/10.1021/ci100062n

Schug TT, Janesick A, Blumberg B, Heindel JJ (2011) Endocrine disrupting chemicals and disease susceptibility. J Steroid Biochem Mol Biol 127:204-215. https://doi.org/10.1016/j.jsbmb.2011.08.007

Shi LM, Fang H, Tong W et al (2001) QSAR models using a large diverse set of estrogens. J Chem Inf Comput Sci 41:186-195. https://doi. org/10.1021/ci000066d

Shizu R, Min J, Sobhany M et al (2018) Interaction of the phosphorylated DNA-binding domain in nuclear receptor CAR with its ligandbinding domain regulates CAR activation. J Biol Chem 293:333344. https://doi.org/10.1074/jbc.M117.806604

Shoichet BK (2004) Virtual screening of chemical libraries. Nature 432:862-865. https://doi.org/10.1038/nature03197

Song Y, Xue X, Wu X et al (2016) Identification of N -phenyl-2-(N -phenylphenylsulfonamido)acetamides as new ROR $\gamma$ inverse agonists:
Virtual screening, structure-based optimization, and biological evaluation. Eur J Med Chem 116:13-26. https://doi.org/10.1038/ ncomms 9833

Soto AM, Sonnenschein C (2010) Environmental causes of cancer: endocrine disruptors as carcinogens. Nat Rev Endocrinol 6:363-370. https://doi.org/10.1038/nrendo.2010.87

Spiteller G (2005) Furan fatty acids: occurrence, synthesis, and reactions. Are furan fatty acids responsible for the cardioprotective effects of a fish diet? Lipids 40:755-771. https://doi.org/10.1007/s1174 5-005-1438-5

Spyrakis F, Cavasotto CN (2015) Open challenges in structure-based virtual screening: receptor modeling, target flexibility consideration and active site water molecules description. Arch Biochem Biophys 583:105-119. https://doi.org/10.1016/j.abb.2015.08.002

Su R, Xiong S, Zink D, Loo L-H (2016) High-throughput imaging-based nephrotoxicity prediction for xenobiotics with diverse chemical structures. Arch Toxicol 90:2793-2808. https://doi.org/10.1007/ s00204-015-1638-y

Toporova L, Balaguer P (2020) Nuclear receptors are the major targets of endocrine disrupting chemicals. Mol Cell Endocrinol 502:110665. https://doi.org/10.1016/j.mce.2019.110665

Trisciuzzi D, Alberga D, Mansouri K et al (2015) Docking-based classification models for exploratory toxicology studies on high-quality estrogenic experimental data. Future Med Chem 7:1921-1936. https://doi.org/10.4155/fmc.15.103

Trisciuzzi D, Alberga D, Mansouri K et al (2017) Predictive structurebased toxicology approaches to assess the androgenic potential of chemicals. J Chem Inf Model 57:2874-2884. https://doi. org/10.1021/acs.jcim.7b00420

Tyagi S, Gupta P, Saini AS et al (2011) The peroxisome proliferatoractivated receptor: a family of nuclear receptors role in various diseases. J Adv Pharm Technol Res 2:236-240. https://doi. org/10.4103/2231-4040.90879

van der Ven LTM, Rorije E, Sprong RC et al (2020) A case study with triazole fungicides to explore practical application of next-generation hazard assessment methods for human health. Chem Res Toxicol 33:834-848. https://doi.org/10.1021/acs.chemrestox.9b00484

Veras Ribeiro Filho H, Tambones IL, Mariano Gonçalves Dias M et al (2019) Modulation of nuclear receptor function: targeting the protein-DNA interface. Mol Cell Endocrinol 484:1-14. https://doi. org/10.1016/j.mce.2019.01.023

Weatherman RV, Fletterick RJ, Scanlan TS (1999) Nuclear-receptor ligands and ligand-binding domains. Annu Rev Biochem 68:559581. https://doi.org/10.1146/annurev.biochem.68.1.559

Weikum ER, Liu X, Ortlund EA (2018) The nuclear receptor superfamily: a structural perspective. Protein Sci 27:1876-1892. https://doi. org/10.1002/pro.3496

Xu HE, Lambert MH, Montana VG et al (1999) Molecular recognition of fatty acids by peroxisome proliferator-activated receptors. Mol Cell 3:397-403. https://doi.org/10.1016/S1097-2765(00)80467-0

Xu L, Sinclair AJ, Faiza M et al (2017) Furan fatty acids-Beneficial or harmful to health? Prog Lipid Res 68:119-137. https://doi. org/10.1016/j.plipres.2017.10.002

Yu K, Bayona W, Kallen CB et al (1995) Differential activation of peroxisome proliferator-activated receptors by eicosanoids. J Biol Chem 41:23975-23983

Publisher's Note Springer Nature remains neutral with regard to jurisdictional claims in published maps and institutional affiliations. 